\title{
Evolutionarily conserved partial gene duplication in the Triticeae tribe of grasses confers pathogen resistance
}

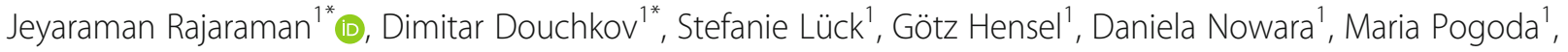 \\ Twan Rutten', Tobias Meitzel', Jonathan Brassac ${ }^{1}$, Caroline Höfle², Ralph Hückelhoven², Jörn Klinkenberg 3 , \\ Marco Trujillo ${ }^{3,6}$, Eva Bauer ${ }^{4}$, Thomas Schmutzer ${ }^{1}$, Axel Himmelbach', Martin Mascher', Barbara Lazzari ${ }^{5}$, Nils Stein?', \\ Jochen Kumlehn ${ }^{1}$ and Patrick Schweizer ${ }^{1 \wedge}$
}

\begin{abstract}
Background: The large and highly repetitive genomes of the cultivated species Hordeum vulgare (barley), Triticum aestivum (wheat), and Secale cereale (rye) belonging to the Triticeae tribe of grasses appear to be particularly rich in gene-like sequences including partial duplicates. Most of them have been classified as putative pseudogenes. In this study we employ transient and stable gene silencing- and over-expression systems in barley to study the function of HVARM1 (for H. vulgare Armadillo 1), a partial gene duplicate of the U-box/armadillo-repeat E3 ligase HVPUB15 (for H. vulgare Plant U-Box 15).

Results: The partial ARM1 gene is derived from a gene-duplication event in a common ancestor of the Triticeae and contributes to quantitative host as well as nonhost resistance to the biotrophic powdery mildew fungus Blumeria graminis. In barley, allelic variants of HVARM1 but not of HVPUB15 are significantly associated with levels of powdery mildew infection. Both HvPUB15 and HVARM1 proteins interact in yeast and plant cells with the susceptibility-related, plastid-localized barley homologs of THF1 (for Thylakoid formation 1) and of ClpS1 (for Clp-protease adaptor S1) of Arabidopsis thaliana. A genome-wide scan for partial gene duplicates reveals further events in barley resulting in stressregulated, potentially neo-functionalized, genes.

Conclusion: The results suggest neo-functionalization of the partial gene copy HVARM1 increases resistance against powdery mildew infection. It further links plastid function with susceptibility to biotrophic pathogen attack. These findings shed new light on a novel mechanism to employ partial duplication of protein-protein interaction domains to facilitate the expansion of immune signaling networks.
\end{abstract}

Keywords: Partial gene duplication, Neo-functionalization, Disease resistance, Triticeae grasses

\section{Background}

Plants respond to pathogen attack by the activation of their innate immunity system, which is triggered by the perception of pathogen-associated molecular patterns (PAMPs) via pattern recognition receptors [1]. Successful plant pathogens manipulate their hosts by complex arsenals of secreted effector proteins, which suppress

\footnotetext{
* Correspondence: rajaraman@ipk-gatersleben.de; dushkov@ipk-gatersleben.de This paper is dedicated in memory of Patrick Schweizer Deceased

'Leibniz Institut für Pflanzengenetik und Kulturpflanzenforschung (IPK Gatersleben), Corrensstrasse 3, D-06466 Stadt Seeland, Germany Full list of author information is available at the end of the article
}

immunity and co-opt cellular host functions for accommodation and nutritional exploitation [2]. Nonhost plant species, on the other hand, exhibit nonhost resistance (NHR), which protects them from the vast majority of attacks by pathogens that have adapted to different, more or less closely related, plant species [3]. The outcome of pathogen-host interactions can vary from immune to highly susceptible, depending on the presence or absence of major resistance genes or on different levels of quantitative host resistance (QR). QR is usually determined by several quantitative trait loci (QTL) and may be partially explained by a manifestation

(c) The Author(s). 2018 Open Access This article is distributed under the terms of the Creative Commons Attribution 4.0 International License (http://creativecommons.org/licenses/by/4.0/), which permits unrestricted use, distribution, and 
of PAMP-triggered immunity (PTI). In contrast to effector-triggered immunity (ETI), it does not confer complete protection but may be more durable in the field [4-6].

All forms of host resistance are temporary results of the co-evolutionary arms race between host plants and their adapted pathogens. As such, pathogens evolve quickly and put enormous selection pressure on host genomes to keep pace with changing virulences [7-10], thereby resulting in strong selective pressure on new resistance and defense genes or gene variants. Besides alternative splicing, gene duplication is an efficient way to create novelty in genomes and is routinely observed for ETI-mediating nucleotide binding domain-leucine rich repeat domain (NB-LRR)-type major resistance genes as well as receptor-like kinases in pairs or clusters of tandem duplicates [11, 12]. Genes can be duplicated as complete or partial copies. In humans, partially duplicated genes have been recognized as a major cause of disease including different forms of cancer [13-15]. The possible contribution of partial gene duplicates to positive traits such as disease resistance is much less examined in animal genetics and apparently unexplored in plants [16-18]. The occurrence of partial gene copies is particularly relevant to the large and highly repetitive genomes of the Triticeae tribe of grasses including Hordeum vulgare ssp. vulgare (cultivated barley), Triticum aestivum (bread wheat), and Secale cereale (rye), which were described to be particularly rich in gene-like sequences including partial duplicates, most of which were classified as putative pseudogenes [19-21].

Cultivated barley is nonhost to the non-adapted wheat powdery mildew fungus Blumeria graminis f.sp. tritici $(B g t)$ but a host of the powdery mildew fungus $B$. graminis f.sp. hordei (Bgh), which causes up to $30 \%$ yield loss in the absence of genetic or chemical control of the disease [22, 23]. The epidemic spread of B. graminis is caused by the asexual propagation of the fungus, with a generation time of 5-7 days and massive production of conidiospores (Additional file 1: Figure S1). The interaction between different barley genotypes and Bgh isolates represents a well-studied model system for a fungal disease caused by an obligate biotrophic pathogen, and a growing number of host-response factors for defense or disease establishment have been identified [24-26]. The genome of $B g h$ was found to encode more than 500 candidate secreted effector proteins [27]. In several pathogens, a growing number of effectors were found to target components of the plant ubiquitination machinery including plant U-box E3 ligases (PUBs) [28-34]. The covalent attachment of single ubiquitin moieties or polyubiquitin chains to lysine residues of eukaryotic protein substrates can have diverse effects on their fate. Ubiquitination most commonly results in the recognition and degradation of tagged proteins by the $26 \mathrm{~S}$ proteasome, but it also mediates endosomal sorting into cellular compartments such as the lysosome or the plant vacuole, or contributes to DNA damage responses [35,36]. The substrate specificity during ubiquitination is determined by the E3 ubiquitin ligases which can be subdivided into three categories, namely HECT, RING/U-box type, and cullin-RING ligases. These proteins mediate ubiquitin ligation in concert with the highly conserved ubiquitin-activating enzyme (E1) and ubiquitin-conjugating enzymes (E2). Due to their central cellular function, components of the ubiquitination system represent central cellular hubs of protein regulation involved in all aspects of plant life. As such, beneficial or parasitic organisms may utilize the ubiquitination machinery [32] to establish susceptible interactions. On the other hand, higher plants exploit ubiquitin-mediated degradation of negative protein regulators of stress-hormone signaling for the initiation of defense responses [36-38].

In a phenotype-driven, transient RNA interference (RNAi) screen for the discovery of Rnr (for Required for nonhost resistance) genes to the non-adapted wheat powdery mildew fungus B. graminis f.sp. tritici (Bgt), we tested more than 631 barley genes, which were mostly associated with up-regulated transcripts in Bgt-attacked barley leaf epidermis [39]. Reduced NHR was reflected by an increased percentage of transformed epidermal cells containing Bgt haustoria. This revealed 10 final $R n r$ gene candidates that significantly enhanced nonhost susceptibility upon silencing. Here we present an extensive evolutionary, genomics, and molecular functional study of the neo-functionalized partial gene copy Rnr5 encoding HvARM1 with homology to plant U-box protein 15 (HvPUB15). Besides its possible role in NHR that allowed its discovery in the NHR RNAi screening, functional analysis suggested $\operatorname{Rn} 5$ as an important factor of QR against the adapted Bgh fungus.

\section{Results \\ Origin and evolution of HvARM1}

Transient single-cell silencing of Rnr5 significantly reduced NHR of barley to Bgt [39]. BlastX analysis revealed the homology of Rnr5 to PUBs. PUBs contain an N-terminal U-box domain and a C-terminal armadillo-(ARM) repeat domain [40, 41]. Although Rnr5 was most closely related to OsPUB15 in rice [42], it does not appear to be the barley ortholog because the encoded protein of 442 amino acids is considerably shorter than a regular PUB and contains only the C-terminal ARM-repeat region as a conserved domain (Fig. 1a). The barley genome also contains a gene for a full-length PUB protein of 831 amino acids with highest similarity to OSPUB15 that was therefore named HvPUB15, whereas Rnr5 was designated as HvARM1 (Table 1). Protein similarity between HvPUB15 and HvARM1 starts at positions L398 and L9 of HvPUB15 and HvARM1, respectively, between the conserved U-box and ARM-repeat 

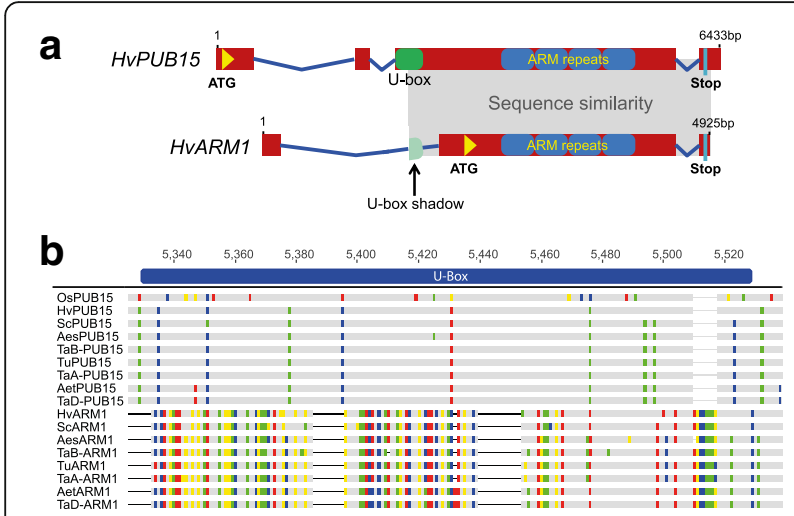

C

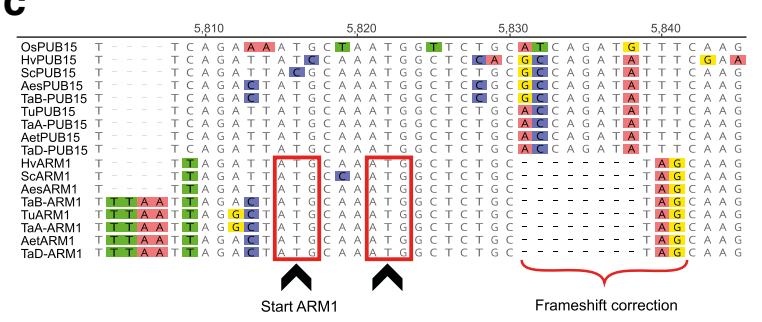

d

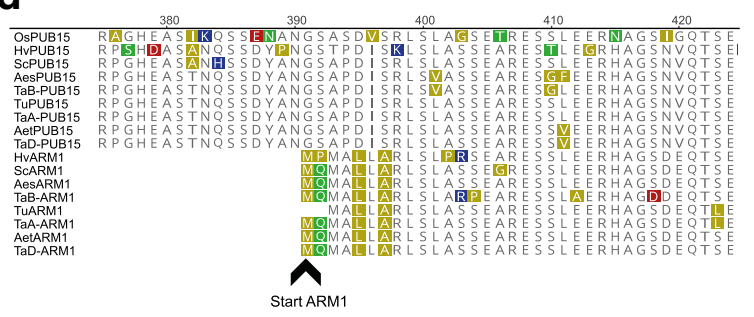

e
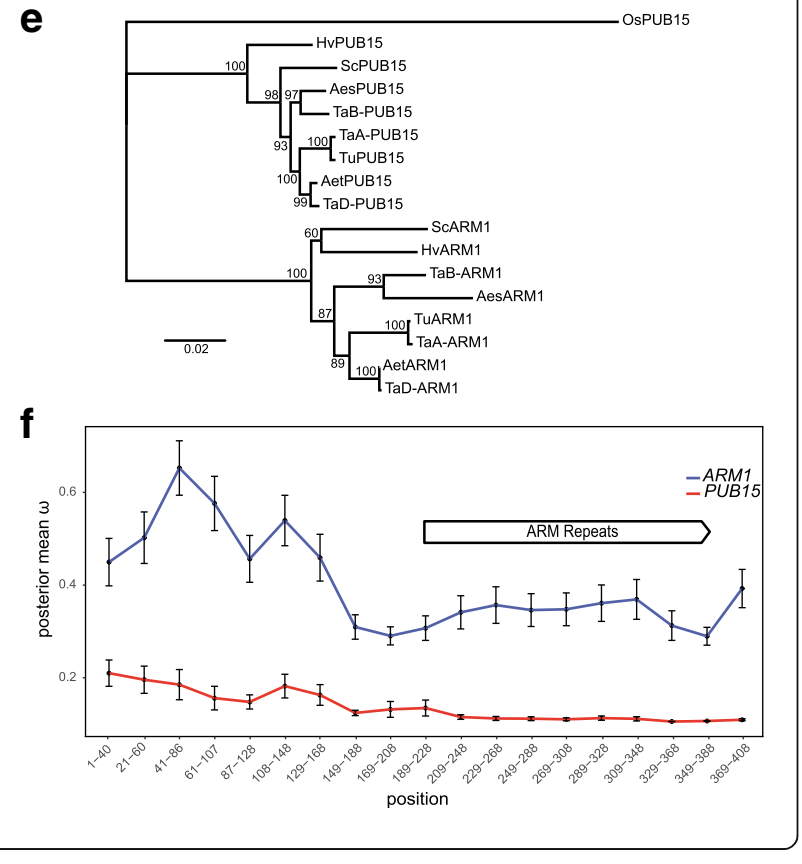

Fig. 1 A partial duplication of the E3 ligase gene PUB15 in Triticeae species gave rise to $A R M 1$. a Schematic view of the genomic structure of HVPUB15 and its partial duplicate HVARM1. Red boxes and blue lines represent exon and intron sequences, respectively. The region of high sequence homology is indicated by light gray shading. $\mathbf{b}$ DNA sequence alignment around the U-box domain of PUB15. Note the absence of sequence alignment (gaps and different colors) in the $5^{\prime}$ end of the U-box in ARM1. c DNA sequence alignment around the translational start of ARM1. The two proposed translation start sites of ARM1 are inside the red frames, and the initial frame of PUB15 is restored by an 8-bp deletion (frameshift correction) downstream from the first 5 amino acids of $A R M 1$ and is indicated by a brace. $\mathbf{d}$ Protein sequence alignment of PUB15 and ARM1 at the N-terminus of ARM1. e Phylogenetic tree of both proteins based on alignment of overlapping PUB15 and ARM1 coding sequences. A maximum likelihood tree with OsPUB15 as outgroup was calculated and bootstrap values (in percent) based on 100 reiterations are indicated along the branches and tree depth (in changes per nucleotide position) by scale bar. $\mathbf{f}$ Conservative selection at the armadillo-repeat domain of ARM1 among Triticeae species. The ratio of non-synonymous to synonymous nucleotide exchanges ( $\omega$ ) among PUB15 and ARM1 genes overlapping region of six Triticeae species plus rice was calculated. Posterior mean $\omega+$ standard error (SE) are reported over 40 non-ambiguous amino acid positions sliding window, with a step size of 20. a-f Species binomial abbreviations: Aes, Aegilops speltoides, Aet, Aegilops tauschii (wild wheat close relatives); Hv, Hordeum vulgare (barley); Os, Oryza sativa (rice); Sc, Secale cereale (rye), Ta, Triticum aestivum (wheat) followed by homeolog orgin, Tu, Triticum urartu (wild wheat close relative). b-d Disagreements to majority consensus are highlighted in color. Accession numbers of publicly available sequences are listed in Additional file 1: Table S10

regions of HvPUB15 (Additional file 1: Figures S2 and S3a). Sequence similarity between the two genes extends upstream from the HvARM1 initiating codon spanning the first intron of $H v A R M 1$, which corresponds to the exon 3 sequence of $H v P U B 15$, until it abruptly ends within the U-box sequence of HvPUB15 (Fig. 1a and b). A further upstream sequence inside $H v A R M 1$ intron 1 as well as the untranslated exon1 sequence did not exhibit significant similarity to any annotated gene or repetitive DNA element in the barley genome. These results strongly suggest that $H v A R M 1$ originated as a partial gene duplicate of HvPUB15. An 8-bp deletion downstream from the first five N-terminal amino acids of HVARM1 restored the initial reading frame (Fig. 1c) because its initiating ATG corresponds to an out-of-frame codon of HvPUB15 (Fig. 1d). Whole genome shotgun (WGS) sequences of five additional species of the Triticeae tribe of grasses, wheat (Triticum aestivum) and its potential wild progenitors Aegilops speltoides, Ae. tauschii, and T. urartu plus rye (Secale cereale), also revealed the presence of HVARM1-like genes, suggesting a monophyletic origin of the partial gene-duplication event in a common Triticeae ancestor dating back at least 15 million (M) years [43] (Fig. 1e). To address the question of whether different evolutionary constraints act on PUB15 and ARM1 genes, we searched both 
Table 1 Sequence overview of HVPUB15 and its partial duplicate HVARM1 in the barley genome

\begin{tabular}{|c|c|c|}
\hline Identifier & HVPUB15 & HVARM1 \\
\hline cDNA clone ID & HO23D08 & $\mathrm{HO} 14 \mathrm{H} 18$ \\
\hline HarvEST assembly \#35 unigene Nr. & 3072 & 3071 \\
\hline Full-coding sequence cDNA Acc. Nr. & AK361754 & AK371875 \\
\hline Morex WGS contig Acc. Nr. ${ }^{a}$ & CAJW010005672 & CAJX010121345 \\
\hline Barke WGS contig Acc. Nr. ${ }^{a}$ & CAJV010187631 & CAJV010188692 \\
\hline Bowman WGS contig Acc. Nr. ${ }^{a}$ & CAJX010851782 & CAJX010121345 \\
\hline High-confidence barley gene $I^{\mathrm{a}}$ & HORVU3Hr1G113910 & HORVU3Hr1G081380 \\
\hline Chromosome $^{\mathrm{b}}$ & $3 \mathrm{HL}$ & $3 \mathrm{HL}$ \\
\hline Position $(\mathrm{Mbp})^{\mathrm{b}}$ & 689.57 & 594.73 \\
\hline Syntenic to Brachypodium distachyon, Oryza sativa, Sorghum bicolor & No & No \\
\hline Syntenic to Ae. tauschii ${ }^{c}$ & Yes & No \\
\hline
\end{tabular}

${ }^{a}$ Most significant BlastN result with $99-100 \%$ identity to genomic sequence of barley (http://webblast.ipk-gatersleben.de/barley/)

${ }^{b}$ Based on high-confidence $(\mathrm{HC})$-gene mapping of the barley reference sequence [72]

'Based on the Ae. tauschii genome https://doi.org/10.1073/pnas.1219082110

orthologous gene groups for footprints of purifying or diversifying selection by calculating $d_{\mathrm{N}} / d_{\mathrm{S}}$ ratios $(\omega)$ at the codon level in a phylogenetic context. Protein sequence conservation among the seven species was high in both the U-box-containing N-terminal and the ARM-repeatcontaining C-terminal parts of PUB15 (Additional file 1: Figure S3b), the existing polymorphisms being in agreement with phylogenetic species distances. By contrast, sequence conservation was reduced among ARM1 proteins (Additional file 1: Figure S3c), most clearly evident when comparing the two wild wheat species. As shown in Fig. If and Additional file 1: Figure S3d, both genes are subjected to purifying selection at the very $\mathrm{N}$-terminus of ARM1 and within the ARM-repeat region. Selection was neutral in ARM1 outside these regions, whereas PUB15 sequences remained under purifying selection along the entire ARM1-overlapping part of the gene. This suggests that the function of ARM1 proteins is restricted to the binding of one or a few protein ligand(s) via their ARM repeats, whereas structural constraints on full-length E3 ligases that have to bind to substrate proteins and mediate the interaction with the highly conserved UBC domain of E2s are probably more stringent.

\section{Allelic variants of HvARM1}

The phylogenetic and functional (see below) data of ARM1 suggest that the gene is under selection for maintaining a quantitative level of resistance among Triticeae species to powdery mildew infection. We therefore analyzed gene variants (alleles) in a diverse collection of barley genotypes (Additional file 2: Tables S1-S3) for significant association with the severity of powdery mildew infection. Table 2 shows significantly associated single-nucleotide polymorphisms (SNPs) as well as gene-haplotype polymorphisms in two diverse, worldwide collections of barley landraces and cultivars. No association of $H v P U B 15$ gene variants with the same trait was found in these populations. This result supports the view that HVARM1 - despite its partial nature - represents a functional gene protecting barley from powdery mildew attack, whereas the cellular functions of $H v P U B 15$ may be more complex.

\section{Function of HvARM1 during powdery mildew attack}

To validate the transient-induced gene silencing (TIGS) effect of $H v A R M 1$ in the nonhost interaction with Bgt [39] and to further assess its role in the interaction with the adapted $B g h$, we generated transgenic plants with silenced HvARM1. In rice, a detrimental effect of the knock-out mutation of OsPUB15 was described that included severe growth retardation and seedling lethality [44]. A similar phenotype was observed in approximately $25 \%$ of transgenic barley events at the $\mathrm{T} 1$ generation (Additional file 1: Figure S4a). These individuals died after a few weeks, suggesting lethality caused by the homozygous transgene that may result in stronger silencing, in line with the failure to identify homozygous T2 or T3 lines. Homozygous lethality could reflect off-target silencing of the potentially housekeeping HvPUB15 gene or an additional, more basal role of HvARM1 in barley vegetative growth and development. The possible off-targeting of HvPUB15 by the RNAi construct was addressed by software-based prediction and by off-target transcript quantification (Additional file 1: Figure S4b and Fig. 2a). Using default settings including end-stability difference and target-site accessibility thresholds, and the HarvEST:Barley assembly \#35 sequence dataset [45], the software si-Fi21 (https://doi.org/10.5447/ ipk/2017/9) predicted 33 and 6 efficient 21-nt small interfering RNAs (siRNAs) for HvARM1 and HvPUB15, respectively. However, the T3 transgenic lines consistently exhibited silencing of $H v A R M 1$, whereas no reduction of 
Table 2 Marker-trait associations of HVARM1 and HvPUB15 in diverse collections of cultivated H. vulgare ssp. vulgare

\begin{tabular}{|c|c|c|c|c|c|}
\hline Gene & Population $^{a}$ & Trait $^{b}$ & Marker $^{\mathrm{C}}$ & Minus $\log (p)^{d}$ & Holm corr. $p^{\mathrm{e}}$ \\
\hline HVARM1 & WHEALBI_LRC & PM_max_2_isol rel_Rol & $\mathrm{H} 02$ & 2.893 & 0.0051 \\
\hline HVARM1 & WHEALBI_LRC & PM_max_2_isol rel_MRX & $\mathrm{H} 02$ & 2.848 & 0.0057 \\
\hline HVARM1 & WHEALBI_LRC & PM_JKI_75_rel_MRX & $\mathrm{H} 02$ & 2.418 & 0.0153 \\
\hline HVARM1 & WHEALBI_LRC & PM_max_2_isol rel_Rol & S3H_594732776 & 2.893 & 0.0051 \\
\hline HVARM1 & WHEALBI_LRC & PM_max_2_isol rel_MRX & S3H_594732776 & 2.848 & 0.0057 \\
\hline HVARM1 & WHEALBI_LRC & PM_JKI_75_rel_MRX & S3H_594732776 & 2.418 & 0.0153 \\
\hline HVARM1 & WHEALBI_CULT & PM_JKI_75_rel_Rol & S3H_594731277 & 3.826 & 0.0006 \\
\hline HVARM1 & WHEALBI_CULT & PM_JKI_75_rel_MRX & S3H_594731277 & 3.460 & 0.0014 \\
\hline HVARM1 & WHEALBI_CULT & PM_max_2_isol rel_MRX & S3H_594731277 & 3.374 & 0.0017 \\
\hline HVARM1 & WHEALBI_CULT & PM_JKI_75_rel_Rol & $\mathrm{H} 01$ & 3.826 & 0.0004 \\
\hline HVARM1 & WHEALBI_CULT & PM_JKI_75_rel_MRX & $\mathrm{H} 01$ & 3.460 & 0.0010 \\
\hline HVARM1 & WHEALBI_CULT & PM_max_2_isol rel_MRX & $\mathrm{H} 01$ & 3.374 & 0.0013 \\
\hline HVPUB15 & WHEALBI_LRC & PM_JKI_242_rel_Rol & $\mathrm{H} 10$ & 0.871 & 0.5379 \\
\hline HVPUB15 & WHEALBI_LRC & PM_JKI_242_rel_Rol & $\mathrm{H} 11$ & 0.684 & 0.6203 \\
\hline HVPUB15 & WHEALBI_LRC & PM_max_2_isol rel_MRX & $\mathrm{H} 10$ & 0.599 & 1 \\
\hline HVPUB15 & WHEALBI_LRC & PM_JKI_242_rel_Rol & S3H_689574119 & 0.814 & 1 \\
\hline HVPUB15 & WHEALBI_LRC & PM_JKI_242_rel_Rol & S3H_689574678 & 0.814 & 1 \\
\hline HVPUB15 & WHEALBI_LRC & PM_JKI_242_rel_Rol & S3H_689575062 & 0.814 & 1 \\
\hline HVPUB15 & WHEALBI_CULT & PM_max_2_isol rel_Rol & S3H_689573944 & 1.055 & 1 \\
\hline HVPUB15 & WHEALBI_CULT & PM_JKI_75_rel_Rol & S3H_689573944 & 1.002 & 1 \\
\hline HVPUB15 & WHEALBI_CULT & PM_JKI_75_rel_MRX & S3H_689573776 & 0.925 & 1 \\
\hline HVPUB15 & WHEALBI_CULT & PM_JKI_75_rel_MRX & $\mathrm{H} 10$ & 0.511 & 0.926 \\
\hline HVPUB15 & WHEALBI_CULT & PM_max_2_isol rel_MRX & $\mathrm{H} 10$ & 0.372 & 1 \\
\hline HvPUB15 & WHEALBI_CULT & PM_max_2_isol rel_Rol & $\mathrm{H} 11$ & 0.359 & 1 \\
\hline
\end{tabular}

Significantly associated SNP- as well as gene-haplotype polymorphisms are indicated in bold

${ }^{a}$ CULT cultivars, $L R C$ landraces

${ }^{\text {b} T h r e e ~ d i f f e r e n t ~ p o w d e r y ~ m i l d e w ~(P M) ~ t r a i t s ~ w e r e ~ r e c o r d e d: ~(1) ~ i n f e c t i o n ~ c a u s e d ~ b y ~ i s o l a t e ~ J K I ~} 75$ relative to internal reference genotypes Morex (MRX) or Roland (Rol), (2) infection caused by isolate JKI 242 relative to MRX or Rol, (3) maximum infection caused by either isolate relative to MRX or Rol

'Per population and gene the three most significant haplotype-trait as well as SNP-trait associations are shown; $H$ haplotype, S SNP

${ }^{\mathrm{d}}$ Negative $\log (10)$ of $p$ value for the null hypothesis of a marker-trait association

${ }^{\mathrm{e} V}$ alues $>1$ of multiple-testing corrected $p$ values are replaced by 1 ; number of SNPs or haplotypes per gene $=$ number of tests.

HvPUB15 mRNA levels was found, suggesting that the transgene expression levels of the selected lines were not sufficient to silence the off-target.

Because HvARM1 was discovered in a TIGS screen for attenuated NHR [39], we first tested T3 progeny of three selected events for susceptibility to Bgt (Additional file 1: Figure S4c). Although there was a considerable variability between individuals per line, two lines exhibited higher susceptibility to the non-adapted fungus as compared to the control group of azygous segregant plants. In general, azygous plants are considered as better controls since they have undergone the same transformation procedures and lost the transgenic construct by segregation. Indeed, the transformation procedure had an impact on the Bgt interaction because the azygous control group was on average more susceptible than the Golden Promise wild type. Figure $2 \mathrm{~b}$ additionally shows that the three selected events were also more susceptible to $B g h$, compared to a population of control plants consisting of azygous segregants plus progeny from three azygous individuals identified in the T2 generation.

Bombardment with gene-specific RNAi and with over-expression (OEX) constructs for a direct comparison of altered HvARM1 versus HvPUB15 expression levels revealed that gene-specific HvARM1 silencing increased the relative susceptibility index (SI) to Bgh (Table 3), in line with the enhanced susceptibility observed in stable transgenic barley T3 plants. On the other hand, we found no significant effects of altering HvPUB15 mRNA levels on the interaction of transformed cells with Bgh, again indicating more complex, homoeostatic rather than defense-related functions of the encoded protein. Following powdery mildew inoculation, endogenous transcript levels of HVARM1 in peeled leaf epidermis were more strongly up-regulated above a basal level of expression compared to HvPUB15 


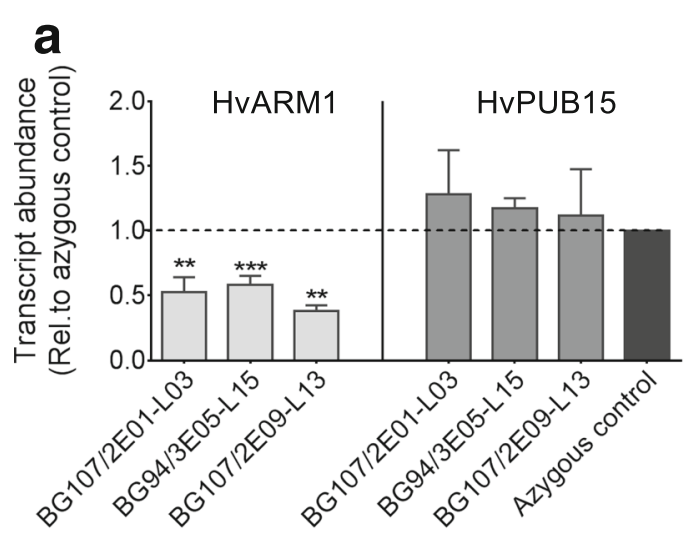

\section{b}

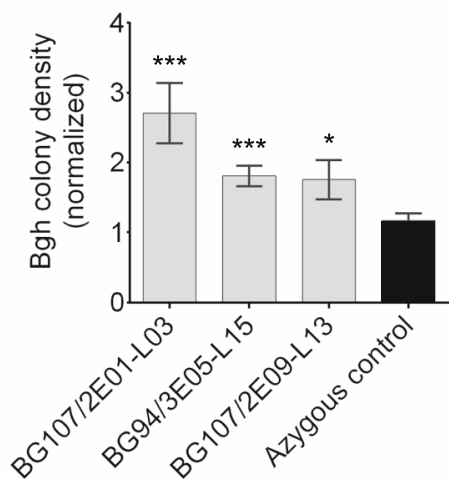

Fig. 2 Silencing of HVARM1 in $\mathrm{H}$. vulgare affects quantitative resistance against B. graminis f.sp. hordei. a Transcript abundance of the HvARM1 target gene and its possible off-target HVPUB15 was determined by RT-qPCR in RNA from leaves of non-inoculated plants. Normalized transcript abundance relative to the HvUBC reference gene encoding an E2 ubiquitin conjugating enzyme (see Additional file 3: Methods S1) was further normalized to the mean value of azygous segregants (set to "1"). Mean values \pm SE from 3 biological replicates (batches of plants sown on different dates) are shown. b Detached second leaves of T3 transgenic barley RNAi plants were inoculated with Bgh and infection was assessed microscopically $48 \mathrm{~h}$ after inoculation. Data represent normalized colony density (number $/ \mathrm{cm}^{2} /$ median of azygous control per experiment) $\pm \mathrm{SE}$ from 2 to 3 biological replications. a, b Statistical differences between transgenic events and azygous plants are indicated by asterisks. ${ }^{*} p<0.05$, ${ }^{* *} p<0.005,{ }^{* * *} p<0.0005$ (Student's $t$ test; two-tailed)

(Additional file 1: Figure S5), which also suggests a defense-related role of HvARM1.

\section{Localization and protein interactions of HvPUB15 and HvARM1}

Fusion proteins of HvARM1 and HvPUB15 with yellow fluorescent protein (YFP) showed a similar fluorescence pattern as non-fused YFP, suggesting nucleo-cytoplasmic localization (Additional file 1: Figure S6, panels a-c), in agreement with the localization of the proposed rice ortholog OsPUB15 [44]. Because the presence of the conserved ARM protein-protein interaction domain in HvARM1 suggests binding to other barley protein(s), we carried out a yeast two-hybrid screening in a prey library from $B g h$-attacked barley leaves using HvARM1 as bait. This led to the identification of six barley proteins that interacted strongly and reproducibly with HvARM1 (Fig. 3a and Additional file 1: Table S8). Out of these six candidates the homologs of Clp-protease adaptor protein ClpS1 and Thylakoid formation 1 protein THF1 of Arabidopsis thaliana [46, 47] also strongly interacted with HvPUB15 (Fig. 3b) and may therefore be ubiquitination substrates of the E3 ligase. By using an in vitro ubiquitination assay we could show that HvPUB15 has ubiquitin ligase activity (Additional file 1: Figure S7). Because HvPUB15 catalyzed the polymerization of ubiquitin chains rather than auto-ubiquitination, it might be an E4 rather than an E3 ligase [48]. The possibility that HvThf1 and HvClpS1 are

Table 3 Effect of TIGS and transient over-expression (OEX) of HVPUB15, HVARM1, and genes encoding their interacting proteins on QR against B. graminis f.sp. hordei

\begin{tabular}{|c|c|c|c|c|c|c|c|}
\hline \multirow[t]{2}{*}{ Bombarded gene } & \multirow[t]{2}{*}{ Proposed function } & \multicolumn{3}{|l|}{ TIGS } & \multicolumn{3}{|l|}{ Transient OEX } \\
\hline & & Rel. SI $(\log 2)^{a}$ & $p(t \text { test })^{b}$ & $\overline{n^{c}}$ & Rel. SI $(\log 2)^{d}$ & $p(t \text { test })^{b}$ & $n^{c}$ \\
\hline HORVU3Hr1G113910 & U-box/ARM E3 protein ligase (HvPUB15) & $0.17 \pm 0.41$ & 0.6950 & 5 & $0.26 \pm 0.19$ & 0.2316 & 7 \\
\hline HORVU3Hr1G081380 & ARM-repeat protein (HvARM1) & $1.16 \pm 0.22$ & 0.0126 & 4 & $-0.01 \pm 0.21$ & 0.9516 & 5 \\
\hline HORVU2Hr1G041260 & Thylakoid formation 1 (Thf1) & $-1.35 \pm 0.59$ & 0.0689 & 6 & $0.47 \pm 12.1$ & 0.0035 & 6 \\
\hline HORVU2Hr1G003460 & ATP-dependent Clp-protease adaptor (ClpS1) & $-0.60 \pm 0.41$ & 0.2168 & 5 & $0.70 \pm 0.06$ & 8.43E-5 & 6 \\
\hline HORVU7Hr1G008760 & Syntaxin HvSNAP34 & $1.14 \pm 0.25$ & 0.0050 & 5 & & & \\
\hline TaPrx $103^{f}$ & Class III peroxidase TaPrx103 & & & & $-1.06 \pm 0.15$ & $6.61 \mathrm{E}-6$ & 14 \\
\hline
\end{tabular}

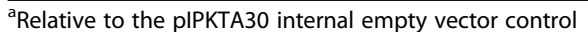

'One-sample $t$ test (two-tailed) of log2-transformed relative susceptibility index (SI) against the hypothetical value " 0 ".

${ }^{\mathrm{c}}$ Number of independent bombardment experiments

d Relative to the pIPKTA09 internal empty vector control

'TIGS of this target gene enhances susceptibility to Bgh and served as positive control [93]

fOver-expression of this gene enhances resistance in barley and wheat against $B$. graminis and served as positive control [106]

Statistically significant effects are highlighted in bold 


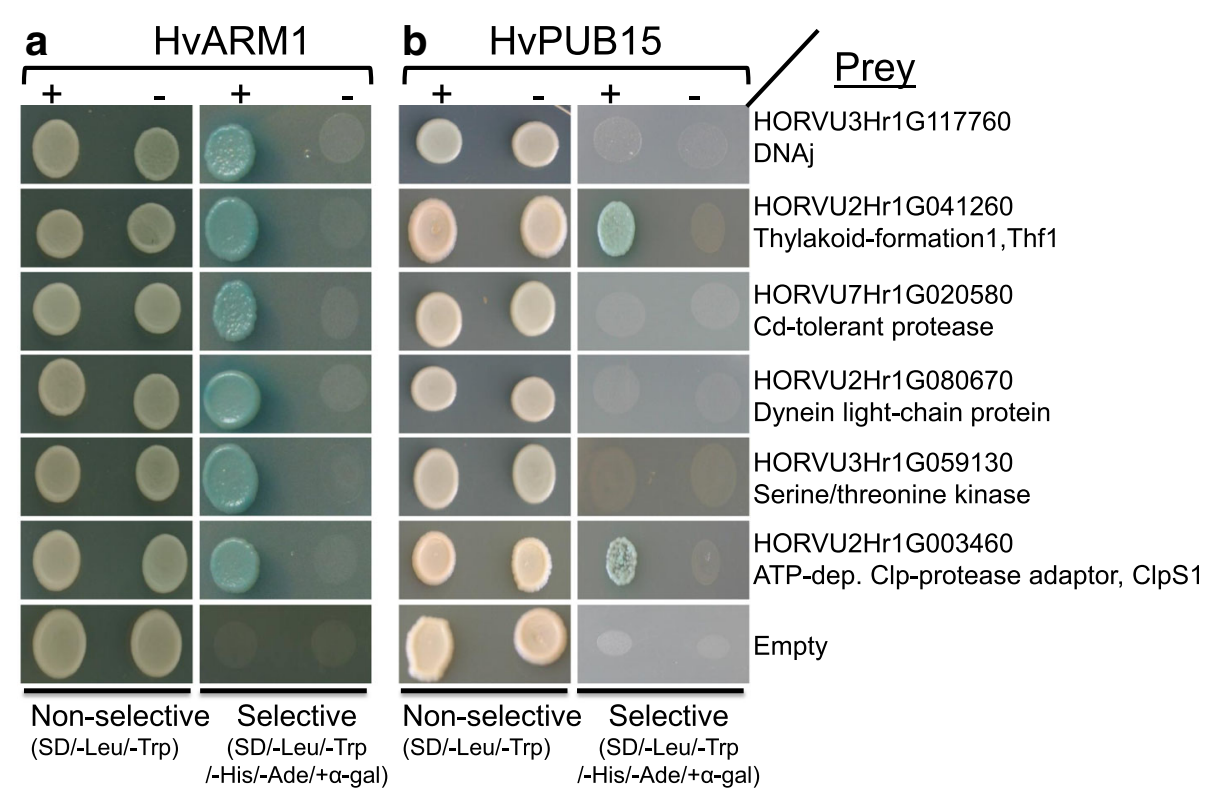

Fig. 3 Proteins of $\mathrm{H}$. vulgare interacting with HVARM1 and HvPUB15 in the yeast two-hybrid system (Y2H). a Full-length HvARM1 was used as bait in a $\mathrm{Y} 2 \mathrm{H}$ screening of a cDNA library derived from Bgh-attacked barley leaves. Growth of yeast on SD-Leu/-Trp confirms the presence of both bait and prey vectors for protein expression. Growth on SD-Leu/-Trp/-His/-Ade indicates protein-protein interaction. No growth of empty bait vector + candidate prey confirms the absence of autoactivation of any prey construct for six final candidates. $\mathbf{b}$ Two of the six candidate protein interactors of HvARM1 also interact with full-length HVPUB15

ubiquitination substrates for HvPUB15 was tested by transient OEX of the HvPUB15 gene together with either HvThf1:YFP or HvClpS1:YFP, followed by the quantification of YFP-fluorescing cells $24 \mathrm{~h}$ after the bombardment. As shown in Table 4, co-expression with HvPUB15 significantly reduced the number of HvThf1:YFP-fluorescing cells, suggesting that HvThf1 is an in vivo substrate to HvPUB15. By contrast, no indication of HvPUB15-mediated degradation of HvClpS1 was found. The possible involvement of these two HvARM1-interacting proteins in the interaction with $B g h$ was tested by TIGS and transient OEX. We observed a trend for reduced susceptibility by silencing and significantly enhanced susceptibility by OEX of HvThf1 (Table 3), which may indicate that the proposed HvPUB15 substrate protein functions as a host susceptibility factor. Transient OEX of $H \nu C l p S 1$ also enhanced susceptibility to $B g h$, although there was no indication of the opposite effect by $H \nu C l p S 1$ silencing. Co-localization experiments of HvThf1-YFP and HvClpS1-YFP C-terminal fusion proteins with the plastid marker Rubisco small subunit [49] confirmed their expected plastid localization (Additional file 1: Figure S6, panels $\mathrm{d}-\mathrm{k}$ ).

In vivo interaction of HvARM1, HvPUB15, and HvPU$\mathrm{B}^{\mathrm{ARM}}{ }^{\mathrm{ARM}}$ (the ARM domain of HvPUB15) with HvThf1 and HvClpS1 was assessed by split-YFP bimolecular functional complementation (BiFC) assays in Agrobacterium-infiltrated Nicotiana benthamiana leaves and by co-immunoprecipitation in $A$. thaliana protoplasts. Figure 4 shows that the transient co-expression of HvPUB15 or HvPUB15 ${ }^{\text {ARM }}$ with either HvClpS1 or HvThf1 gave rise to BiFC (YFP) signals primarily in epidermal cells. The localization patterns of the fluorescence signals indicated that the proteins interacted in

Table 4 Degradation of putative HvPUB15 substrate proteins by transient OEX of HvPUB15

\begin{tabular}{|c|c|c|c|c|c|c|}
\hline \multirow{2}{*}{$\begin{array}{l}\text { Co-bombarded } \\
\text { plasmids }\end{array}$} & \multicolumn{3}{|l|}{ Thf1:YFP } & \multicolumn{3}{|l|}{ ClpS1:YFP } \\
\hline & Rel. cell no. $(\log 2)^{a}$ & $p(t \text { test })^{b}$ & $\overline{n^{c}}$ & Rel. cell no. $(\log 2)^{a}$ & $p(t \text { test })^{b}$ & $n^{c}$ \\
\hline pIPKTA09 & 0 & - & 3 & 0 & - & 4 \\
\hline HVPUB15 & $-0.59 \pm 0.11$ & 0.0365 & 3 & $0.03 \pm 0.28$ & 0.9030 & 4 \\
\hline HvPUB15 + HvARM1 & $-0.42 \pm 0.07$ & 0.0327 & 3 & $-0.64 \pm 0.56$ & 0.3334 & 4 \\
\hline HVARM1 & $-0.30 \pm 0.31$ & 0.4357 & 3 & $0.33 \pm 0.19$ & 0.8815 & 3 \\
\hline
\end{tabular}

${ }^{a}$ Number of YFP-fluorescing cells (relative to the empty vector control pIPKTA09) expressing HvThf1:YFP or HvClpS1:YFP constructs in the presence of different co-bombarded plasmids

"One-sample $t$ test (two-tailed) against the hypothetical value " 0 "

cNumber of independent bombardment experiments

Statistically significant effects are highlighted in bold 


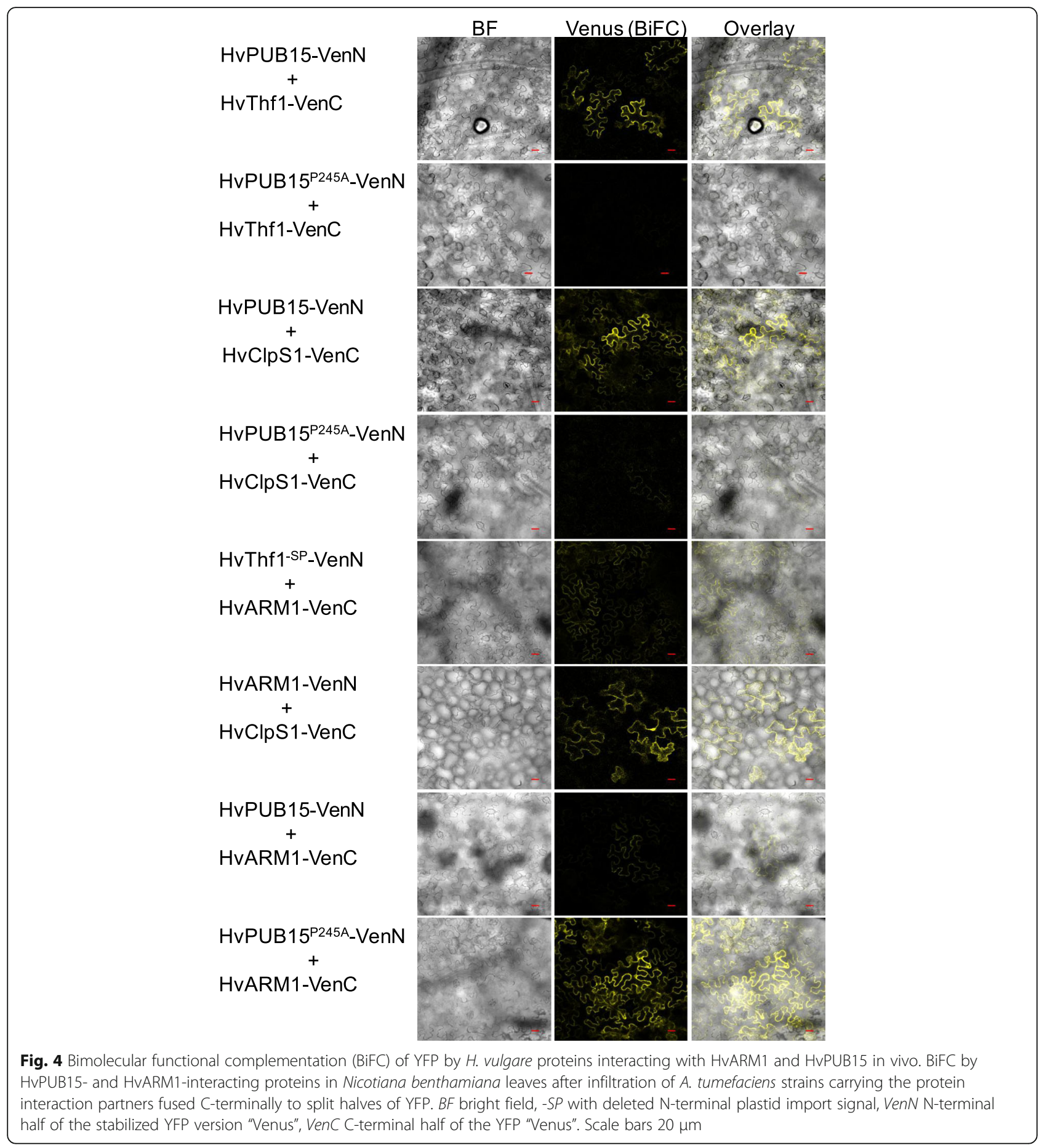

the cytoplasm, which was confirmed by the absence of co-localization with the plastid marker protein $35 \mathrm{~S}: \mathrm{SSU}_{1-79}-\mathrm{mCherry}$. The BiFC signals were abolished or strongly reduced by using the U-box mutant HvPUB $15^{\mathrm{P} 245 \mathrm{~A}}$ as an interaction partner, suggesting specificity of the interaction. HvARM1 also interacted with $\mathrm{HvClpS1}$ and HvThf1. Moreover, interactions were observed between HvPUB15 and HvARM1, and here the
HvPUB15 U-box mutation increased BiFC signals instead of reducing them. The specificity of the interaction was further confirmed using additional controls and quantitative fluorescence measurement (Additional file 1: Figures S8 and S9). Co-immunoprecipitation experiments in $A$. thaliana protoplasts of cMyc-tagged HvARM1 and HvPUB15 ${ }^{\text {ARM }}$ together with either HvThf1 or HvClpS1 confirmed in vivo interaction of $\mathrm{HvPUB} 15^{\text {ARM }}$ with 
HvThf1, HvARM1 with HvThf1, and HvARM1 with HvClpS1 (Fig. 5). Taken together, the results suggested in vivo interaction of HvPUB15 with HvClpS1 and HvThf1, whereby the presence of an intact U-box was required for the interaction. In addition, HvARM1 as well as the ARM -domain of HvPUB15 interacted with HvClpS1 and HvThf1. One of the HvPUB15-interacting proteins, HvThf1, was identified as a potential ubiquitination substrate and as a host susceptibility factor to $B g h$.

\section{Genome-wide search for expressed partial gene duplicates}

Does the partially duplicated gene pair of PUB15 and ARM1 represent a unique case in Triticeae genome evolution, or could we find indications for additional partial gene duplicates with putative functions? To address this question we conducted a genome-wide search for pairs of full-length complementary DNA (cDNA) sequences with

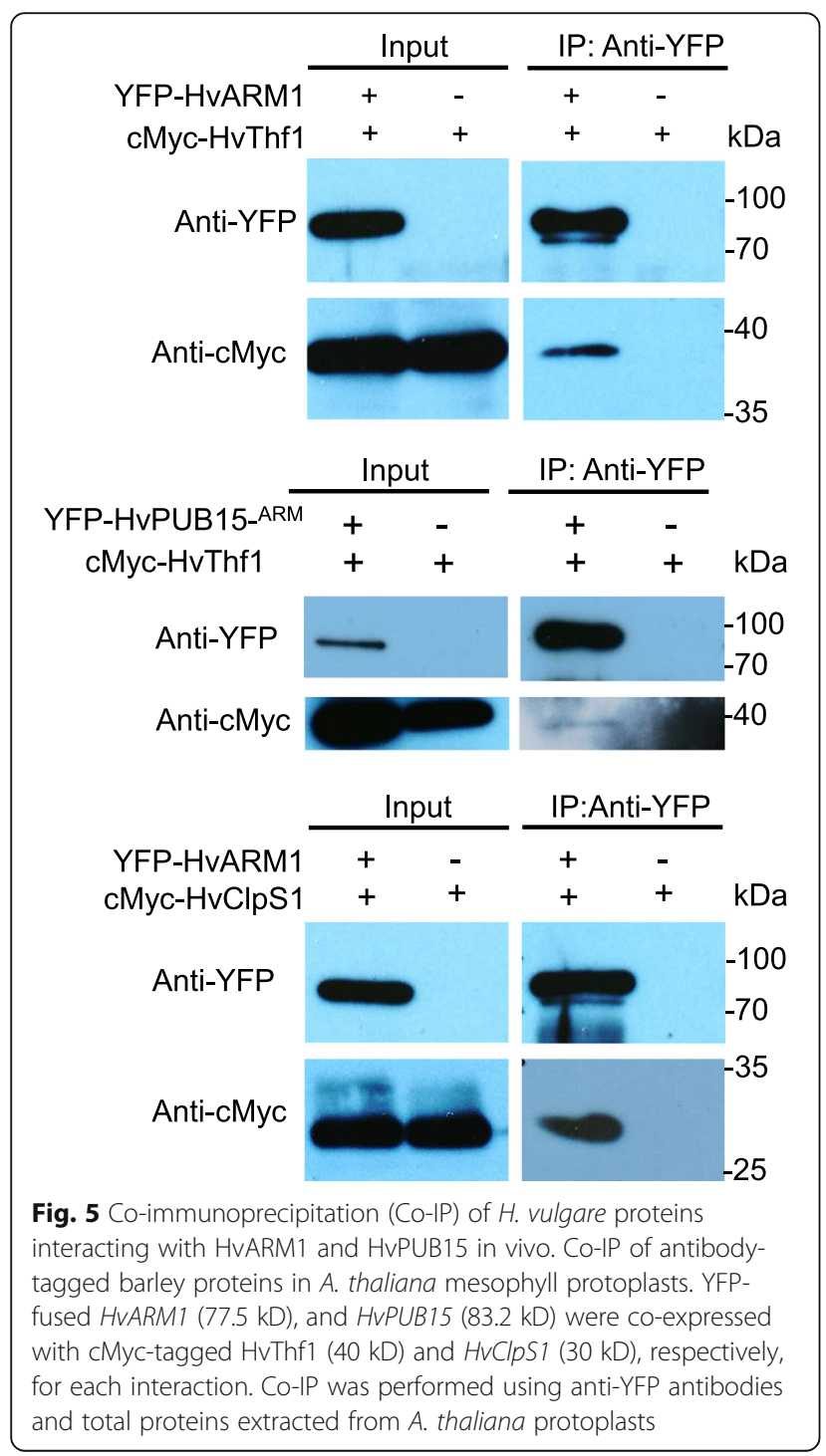

high sequence similarity but clearly different lengths of their longest open reading frames. The rationale behind this approach was to select for partially duplicated or rearranged genes that are expressed and therefore more likely to fulfill a biological role. Starting with a library of 23,614 full-length cDNA sequences (http://barleyflc.dna.affrc.go.jp/bexdb/), we found 1154 matching cDNA pairs with a sequence identity of $80-99 \%$. A subsequent tBlastx analysis of these pairs revealed 205 pairs with a length difference of matching open reading frames of $>25 \%$. After further filtering steps to exclude non-spliced transcripts and chimeric as well as partial clones, we identified eight expressed pairs of putative, partially duplicated genes including HvPUB15/HvARM1 (Additional file 2: Tables S4 and S5 and Additional file 1: Figure S13). A majority of these are localized at non-tandem positions in the barley genome (five or more gene models apart from each other, or on different chromosomes). Three genes encode proteins from families known to be involved in plant-pathogen interactions: PUB15 plus two receptor-like kinases. Besides the pair of ARM1 and PUB15 we found two more gene pairs giving rise to full-length and truncated proteins, respectively, which are conserved across Triticeae species (Fig. 6a). The truncated open reading frames of one of these pairs encoding a receptor-like kinase are caused by a 19-bp deletion in barley reconstituting a stop codon, or by stop codon mutations approximately 200 bp further downstream in T. aestivum and S. cereale, which mark the insertion of a non-coding genomic sequence. The truncated open reading frames of the second pairs are caused by the insertion of approximately $2 \mathrm{~kb}$ of a non-coding sequence. Finally, although this was not a criterion for their selection, several transcripts encoding truncated proteins were up-regulated by powdery mildew attack (Fig. 6b and Additional file 2: Table S6). Therefore, these rearranged or partial gene duplicates in addition to HvARM1 might have evolved to fulfill new functions in Triticeae species.

\section{Discussion}

At least six species of the Triticeae tribe of grasses possess $A R M 1$, a partial gene copy of a U-box/ARM-repeat E3 ligase closely related to OsPUB15 of rice [44]. The rice genome also contains a number of "ARM-repeat only" genes, but none of them appears to represent a partial copy of OsPUB15, because BlastN analysis of the ARM-repeat region of OsPUB15 (positions 2000-2952 in cDNA Acc. AK106557.1) at the National Center for Biotechnology Information (NCBI) did not produce significant hits for any other rice gene. By contrast, the same query sequence revealed $H v A R M 1$ as the most significant hit (86\% identity) in barley. Sequence analysis in cultivated barley, wheat, and rye, and in three diploid wild wheat species suggest a monophyletic origin of 


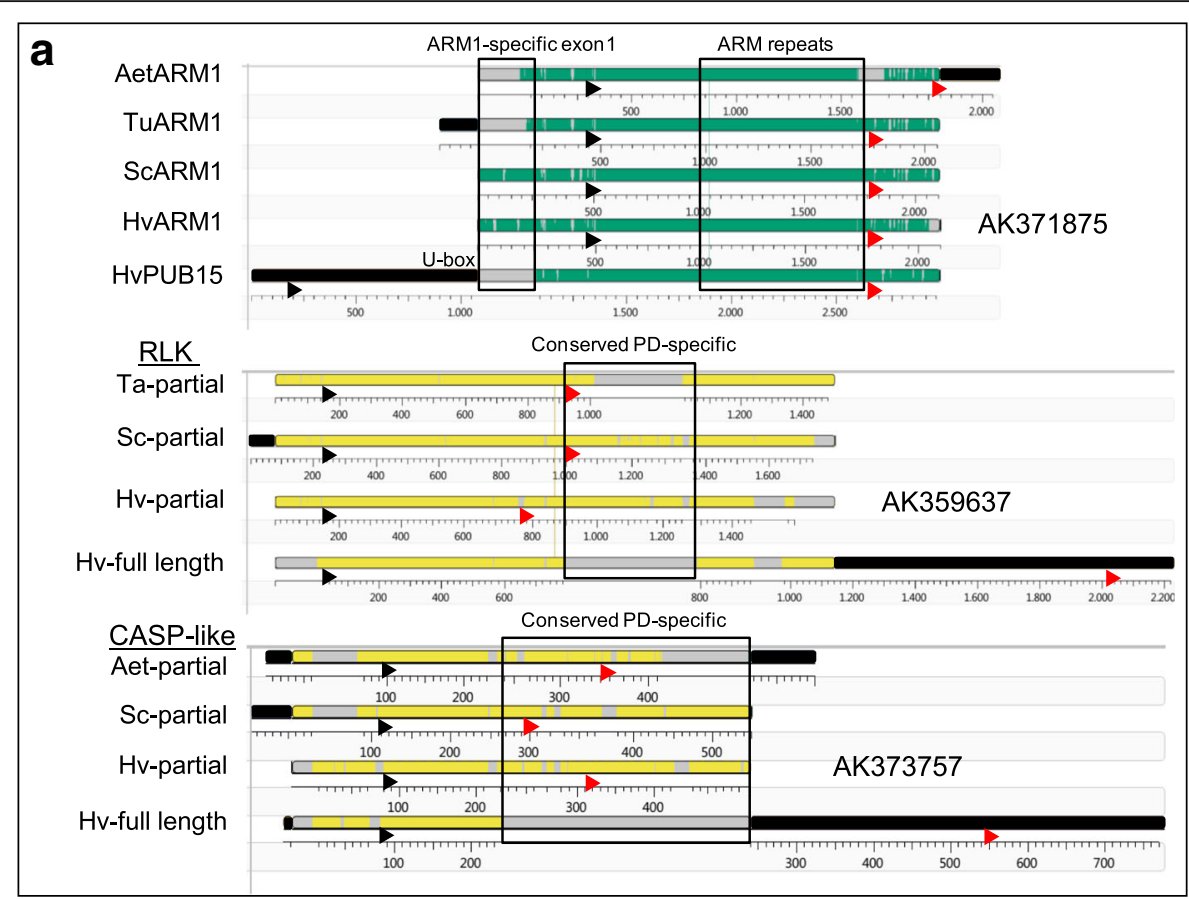

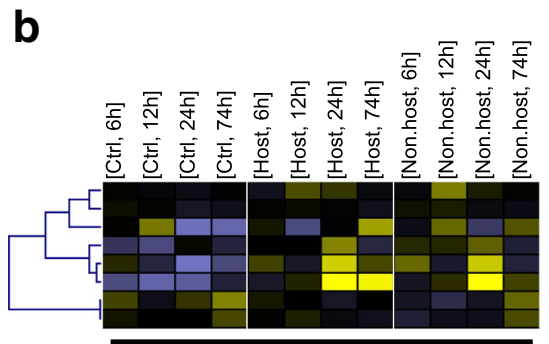

Partial duplicate

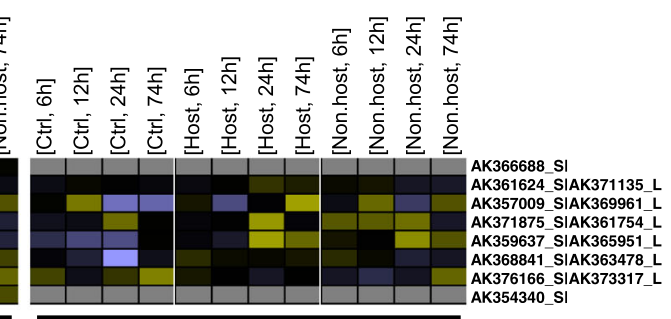

Full-length gene

$-1.5$

Fig. 6 Genome-wide analysis of expressed and conserved gene duplicates. a Pairs of barley cDNA encoding full-length proteins and partial copies, respectively, which are conserved across Triticeae, were aligned using MAUVE algorithm. The dark green shading in ARM1 or yellow shading in the rest indicates aligning sequences, whereas gray shading shows gaps. Black and red arrowheads indicate start- and stop-codon positions of the corresponding open reading frames, respectively. Non-aligning sequences (in black) at the beginning or end were automatically detached from the alignment blocks. Only the first $500 \mathrm{bp}$ of the CASP-like duplicates giving rise to truncated proteins are shown. Scale below alignments, sequence length in bp; PD partial duplicate. Aet, Aegilops tauschii; Tu, Triticum urartu; Sc, Secale cereale; Hv, Hordeum vulgare. For annotation and further details see Additional file 2: Table S4. b Transcript regulation in peeled barley leaf epidermis by Bgh (adapted host pathogen) or Bgt (nonhost pathogen). Total RNA was isolated at the time indicated after inoculation and hybridized to the Barley Gene Expression Array of Agilent. For the link of cDNA accession number to Agilent probe IDs, see Additional file 2: Table S4. Transcript data have been submitted to ArrayExpress (Acc. E-MTAB-2916). Hierarchical clustering of gene-median-centered, normalized signal intensities is shown. The color scale ranges from $\log (2)-1.5$ to 1.5. Mean signal intensities from three independent inoculation experiments are shown

ARM1. The large and highly repetitive genomes of the cultivated Triticeae species barley, wheat, and rye are known to be rich in gene-like sequences including partial duplicates, and most of them were classified as putative pseudogenes $[19,20]$. The classification criteria for these putative pseudogenes were (1) non-syntenic map positions among grasses and (2) unique occurrence in one species or in one of the three subgenomes of hexaploid wheat. Illegitimate meiotic crossing over and subsequent sequence capture by transposable elements, as well as random sequence insertion during non-homologous end joining for double-strand break DNA repair, are the two proposed major events leading to non-tandem (partial) gene duplicates [50]. By contrast, sub- or neo-functionalized, expressed and full-length gene duplicates often exist as tandemly repeated gene pairs or clusters of genes, as a result of unequal crossover during meiosis that is often followed by gene conversions [51, 52]. As shown in 
Table 1, the full-length genes HvPUB15 and AetPUB15 share syntenic map positions on the long arm of homologous chromosome group 3 [53, 54]. The partially duplicated HvARM1 gene was mapped at a distance of approximately $95 \mathrm{Mbp}$ from HvPUB15 on chromosome $3 \mathrm{H}$, and all six analyzed Triticeae ARM1 genes contain a non-repetitive, unknown sequence in exon 1 that is not present in the corresponding PUB15-like genes. Taken together this suggests that an event of DNA double-strand break repair in a common ancestor of Triticeae species gave rise to ARM1.

Gene duplication followed by neo-functionalization is a source of generation of new genes in plants and has been reported for individual genes or at a genome level [55-58]. However, there is no report of a "partial" gene duplication followed by neo-functionalization, and our results presented here suggest that $A R M 1$ escaped pseudogenization and took over a new biological function in defense against powdery mildew fungi and perhaps other pathogens: First, the genomes of six species belonging to four different genera maintained the partial gene copy with a high degree of sequence conservation at the ARM-repeat region. Second, in all six species ARM1 is supported by perfectly matching expressed sequence tag (EST) sequences or other transcriptome data, demonstrating that the corresponding genes are actively transcribed. In barley, transcript regulation data suggest a gain of function of HVARM1 in terms of a more pronounced pathogen-induced accumulation in the epidermis compared to HvPUB15 (Additional file 1: Figure S5). Third, all ARM1 sequences are characterized by intact open reading frames starting approximately in the middle part of the PUB15 protein and extending to its C-terminus. Further, ARM1 is subjected to a purifying selection at the $\mathrm{N}$-terminus and within the ARM-repeat region, while the selection is neutral outside these regions (Fig. 1f). This proposes that the function of ARM1 proteins is probably restricted to protein-protein interactions via their ARM repeats, where maintaining a high degree of sequence conservation seems to be of a certain evolutionary importance. Due to their non-functional nature and no selective pressure, the ratio of non-synonymous to synonymous amino acid substitution value should be $\sim 1$ for pseudogenes. In contrast, the ARM1 values are well below 1 in the overlapping region of PUB15 (Fig. 1f). Four, transient OEXs of HvARM1 without the predicted ATG translation-initiation codon $\left(H v A R M 1^{\triangle A T G}\right)$ eliminated the transgene effect, demonstrating that it was caused by translated HvARM1 protein (Additional file 1: Figure S14). Mutating randomly selected but highly conserved amino acids in the ARM-repeat domain of HvARM1 (HvARM1 $^{\mathrm{L} 286 \mathrm{H}}$ and HvARM1 ${ }^{\mathrm{L} 308 \mathrm{~K}}$ ) significantly affected the relative SI towards susceptibility to Bgh (Additional file 1:
Figure S14). This suggests that the ARM-repeat domain in HvARM1 is essential for its function. Fifth, allelic variants of $H v A R M 1$ were found to be significantly associated with the severity of powdery mildew infection in collections of locally adapted barley landraces and diverse cultivars (Table 2 and Additional file 2: Table S1). In both collections the most significant SNPs were associated with clear and statistically significant differences in Bgh infection $(41 \%$ versus $57 \%, p=0.00037$ in collection WHEALBI_LRC; $35 \%$ versus $51 \%, p=0.023$ in collection WHEALBI_CULT). The significant SNP in the landrace collection was located in the $5^{\prime}$ untranslated region of the HvARM1 transcript, whereas the significant SNP in the cultivar collection causes a glycine-to-valine change at position 437 of the encoded protein. The cultivars carrying the corresponding significant, resistance-associated haplotype $\mathrm{H} 01$ were derived from very different regions of the world and therefore probably not similar by descent. The complete absence of association of HvPUB15 alleles with Bgh infection furthermore supports the view that the E3 ligase primarily has important housekeeping functions such as quality control and turning over of plastid-localized proteins [59], with no adaptation flexibility during pathogen co-evolution.

Functional tests of HvARM1 by transient OEX in wheat suggested a resistance-related role during the interaction with adapted and non-adapted powdery mildew fungi (Table 5). Similar to the results presented here, a resistance-enhancing effect was found by OEX of the ARM domain of the AtPUB13 gene in A. thaliana, which is involved in protein degradation of the flagellin PAMP receptor FLS2 [60]. Transgenic plants ectopically over-expressing only the ARM domain of the AtPUB13 phenocopied the atpub12/13 double-mutant effect of enhanced pathogen resistance by blocking the AtPUB12/13-mediated FLS2 degradation. In the current study, our data point out that in barley and other Triticeae species, a novel partial gene-duplication event followed by neo-functionalization of $A R M 1$ has resulted in expression of a single ARM domain as a natural mechanism for enhancing disease resistance to powdery mildew. Further, a study in human antiviral immunity response suggests that partial duplication of protein-protein interaction domains could facilitate the extension of novel immune signaling pathways [18]. Besides

Table 5 Transient over-expression of HVARM1 enhances resistance in $T$. aestivum against $B$. graminis f.sp. tritici

\begin{tabular}{|c|c|c|c|}
\hline Bombarded gene & Relative SI $(\log 2)^{a}$ & $p(t \text { test })^{b}$ & $n^{c}$ \\
\hline HVARM1 & $-0.37 \pm 0.12$ & 0.0107 & 16 \\
\hline${ }^{\mathrm{d}} H V A R M 1^{\triangle A T G}$ & $0.19 \pm 0.13$ & 0.2168 & 5 \\
\hline
\end{tabular}

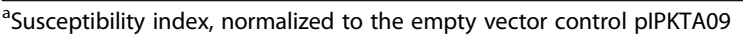
and log2-transformed

bne-sample $t$ test (two-tailed) of log2-transformed relative SI against the hypothetical value " 0 "

'Number of independent bombardment experiments

${ }^{\mathrm{d}}$ Negative control construct without translation start codon 
a putative antagonistic role to PUB15 (see below), ARM1 might also function as a decoy inactivating or trapping pathogen effectors [61]. The recent report of partial effector target-gene duplicates fused to NB-LRR-type resistance genes, which function as single-domain decoys, is reminiscent of the single-domain ARM1 gene described here, although the latter exists as an unfused partial copy [62]. Regarding the full-length gene PUB15, a defense-related role was proposed in rice because OEX of OsPUB15 caused spontaneous defense responses and increased pathogen resistance [63]. We could not confirm a defense-related role of HvPUB15 by TIGS or transient OEX in Bgh-attacked barley (Table 3), but this might reflect multiple and balancing effects of its mis-expression, especially if it fulfills additional, housekeeping functions. The reported lethality of OsPUB15 mutations in rice [44] supports PUB15 as a housekeeping gene, which might be co-opted by Bgh for host accommodation.

The HvARM1 and HvPUB15 proteins interacted in yeast and in plants with the plastid-localized proteins HvClpS1 and HvThf1, and both appear to be susceptibility-related factors based on TIGS and transient OEX results (Table 3). The observation that transcripts of both $H \nu C l p S 1$ and $H \nu T h f 1$ were down-regulated in the epidermis of powdery mildew-attacked leaves might reflect an attempt of the plant to reduce the levels of susceptibility-related factors (Additional file 1: Figure S10 and Additional file 2: Table S7). In contrast to HvClpS1, the degradation of HvThf1 appeared to be mediated by HvPUB15, which suggests this protein as the strongest candidate for a susceptibility-related process involving HvPUB15 and being antagonized by HvARM1. However, because HvPUB15/HvARM1 co-expression did not suppress PUB15-induced HvThf1:YFP degradation, we cannot propose a simple model for a direct antagonistic mode of action of HvARM1. The THF1 protein of A. thaliana was found to be localized in the plastid stroma and at its outer membrane facing the cytoplasm, where it was proposed to play a role in sugar sensing [46]. This is relevant with respect to the high demand of powdery mildew-infected cells for energy equivalents to transport large amounts of glucose into haustoria, a process that depends on SWEET sugar transporters and other factors [64-66]. Further support for the involvement of Thf1 in disease responses comes from the finding that the closest wheat homolog to $H v T h f 1$, designated as TaToxABP1, is a binding protein and a target of Toxin A produced by the necrotrophic, tan-spot fungal pathogen Pyrenophora tritici-repentis [67]. Toxin A treatment also triggered an oxidative burst in leaves of wheat and barley [68,69], thereby providing a link of Thf1 function with reactive oxygen species (ROS) control, at least in chloroplasts, and proposes a mode of action of Toxin A. Also, the interaction of the Thf1 protein with I2-like coiled-coil (CC) domains of several
NB-LRR-type resistance proteins leading to their destabilization has been reported [70]. Finally, the link of protein turnover by proteasomal degradation with chloroplast biology was recently established by reports on the role of the closest HvPUB15 homolog in A. thaliana designated as AtPUB4, and of AtCHIP, in plastid quality control and degradation of the caseinolytic plastid peptidase AtClpP4, respectively [42, 59, 71]. Mutants of AtPUB4 showed reduced resilience against abiotic stress, indicative of compromised plastid-based control of ROS generation. Plants silenced in or over-expressing AtCHIP exhibited a chlorotic phenotype indicating a strict requirement of accurate control of AtClpP4 levels for cellular homoestasis. In contrast to Thf1, no published information supporting a role of ClpS1 in plant-pathogen interactions is currently available.

Besides the PUB15/ARM1 gene pair, we found evidence for seven additional gene-duplication events across the barley genome that gave rise to novel, expressed genes encoding truncated proteins (Additional file 1: Figure S13). This number may be underestimated because the search was based on a library of 23,614 full-length cDNA clones, which covers approximately $50-66 \%$ of the entire predicted gene space. A more comprehensive study of partial gene duplications will have to await improved gene models of the barley reference sequence, as compared to the current annotation [72]. The PUB15/ARM1 gene pair may also not be the only case of evolutionarily conserved duplication/ gene rearrangements in Triticeae, because we also found similarly conserved events in a receptor-like kinase and a CASP-like protein (Fig. 6). Future expression studies and functional tests of these partially duplicated or rearranged genes across Triticeae may reveal a more comprehensive picture of their potential to support host survival.

\section{Conclusion}

The results presented here suggest that $A R M 1$ is a case of gene neo-functionalization after a non-tandem, partial gene-duplication event that gained a role in quantitative resistance against $B$. graminis and maybe other pathogenic fungi. The ARM1 most likely originates from a partial duplication of the E3 ligase PUB15, which occurred in a common ancestor of the Triticeae tribe of grasses. At least in barley, the HvARM1-interacting protein and proposed substrate of HvPUB15, the plastid-localized HvThf1, links susceptibility to biotrophic pathogens with homeostatic protein function in plastids. Our findings shed new light on a novel mechanism to employ partial duplication of the protein-protein interaction domain to facilitate the expansion of immune signaling networks. The genome-wide search for further neo-functionalized gene duplicates encoding truncated proteins may uncover a yet poorly explored aspect of plant genome dynamics, which might be relevant for plant-stress responses in general and for plant-pathogen co-evolution in particular. 


\section{Methods}

A more detailed description of materials and methods used in this study is provided in Additional file 3: Methods S1.

\section{Plant and fungal material}

TIGS and transient OEX experiments were done in 7-day-old seedlings of spring barley Golden Promise, except for OEX of site-directed mutagenesis (SDM) and TIGS of HvThf1 and HvClpS1 where the closely related genotype Maythorpe was used. Stable transgenic barley plants of cv. Golden Promise were generated as described [73]. Bombarded leaf segments or transgenic plants were inoculated with Swiss Bgt field isolate FAL 92315, or Swiss $B g h$ field isolate CH4.8 throughout the study.

\section{Sequence alignment, phylogenetic analysis, and estimation of pressures of selection}

PUB15 and ARM1 orthologs were obtained from five Triticeae species, besides barley, including Secale cereale [21, 74], Triticum aestivum [75], and its three potential wild progenitors T. urartu (A genome), Aegilops speltoides (B genome), and Ae. tauschii (D genome). The sequences were retrieved by BlastN search of the $\mathrm{H}$. vulgare sequences (AK361754 and AK371875, respectively) against the whole genome assembly databases (http:// webblast.ipk-gatersleben.de/ryeselect/ for S. cereale and https://urgi.versailles.inra.fr/blast/blast.php for $T$. aestivum and its relatives). The rice ortholog, OsPUB15 (XM_015795011), was downloaded as outgroup sequence. All 17 coding sequences could be fully acquired but for the Ae. speltoides ARM1 sequence lacking the last exon.

The sequences were aligned with MAFFT v7.308 [76] using the default settings within Geneious 10.0.9 (https:// www.geneious.com) [77] followed by manual adjustment. The model of sequence evolution was determined with jModeltest 2.1.10 [78]. The best-fit model, identified with the Akaike information criterion AIC [79, 80], was the general time-reversible (GTR) [81] with rates variation according to a gamma distribution [82]. The maximum likelihood (ML) phylogenetic tree was calculated with RAxML v8.2.7 [83] using the GTRGAMMA model and 100 bootstrap replicates (options $-\mathrm{f}$ a and $-\mathrm{x}$ ).

Pressures of selection were investigated at the codon level throughout the phylogeny for both proteins separately. The pressure of selection can be estimated by $\omega$ (non-synonymous substitution rate divided by synonymous substitution rate, $\left.d_{\mathrm{N}} / d_{\mathrm{S}}\right)$. An $\omega<1$ suggests that the site is under negative, or purifying, selection, while an $\omega>1$ indicates that positive selection is occurring, and $\omega=1$ for neutral changes. Values of $\omega$ were estimated for each non-ambiguous codon using the codeml program within the package PAML4.9 $\mathrm{h}$ [84]. Following Jeffares et al. [85], codon site models M0 [86, 87], allowing only one class of $\omega, \mathrm{M} 1 \mathrm{a}[88,89]$, allowing two categories of sites $\left(0<\omega_{0}<1\right.$ and $\omega_{1}=1$ with proportions $\mathrm{p}_{0}$ and $\mathrm{p}_{1}=$ $\left.1-\mathrm{p}_{0}\right)$, and M2a $[88,89]$, which includes a proportion of sites under positive selection, were tested. Likelihood ratio tests (LRTs) were performed to compare models M0 and M1a, as a test for variation of $\omega$ among sites, and models M1a and M2a, as a test for positive selection, against a $\chi^{2}$ distribution (with one and two degrees of freedom, respectively). Both proteins showed variations of $\omega$ among sites with M1a versus M0 LRTs significant. But with nearly identical likelihoods for models M1a and M2a, PUB15 and ARM1, though to a lesser extent, proved to be under purifying selection with a small portion of sites under neutral selection. Sequence information is available at https://doi.org/10.6084/m9.figshare.c.4092686.v1.

\section{Exome capture sequencing}

Genomic DNA was extracted from barley leaf material from a single plant for each accession and used for the hybridization with the barley SeqCap Ez oligo pool (Design Name: 120426_Barley_BEC_D04, [54]. Quality-trimmed reads were mapped to the reference genome (http://webblast.ipk-gatersleben.de/barley_ibsc/downloads/) with Burrows-Wheeler Aligner (BWA) v0.7.5a using the mem algorithm with default parameters [90] and retaining only properly paired reads. Variant calling and realignment around indels were performed with Genome Analysis Toolkit (GATK), version 2.7.4 (https://software.broadinstitute.org/gatk/). Variant calls were filtered for high quality and $\geq 80 \%$ of samples being represented at each locus, and a dataset of 449,585 SNPs was produced, suitable for genetic association analysis of the two genes under investigation (full information about genome-wide variants from this dataset will be published elsewhere).

\section{Association genetic analysis}

Association of SNP and gene haplotypes (marker) of HvARM1 and HvPUB15 with the severity of Bgh infection (trait) was calculated based on genetic and phenotypic data of two diverse collections of cultivated barley $(H$. vulgare ssp. vulgare). Bgh infection values were determined in a detached leaf assay using second leaves of approximately 12-day-old seedlings, as described [91]. First, a worldwide collection of 76 landraces (WHEALBI_LRC) was inoculated either with isolate JKI-75 or JKI-242, which exhibit a complex and complementing virulence spectra [92]. Second, a worldwide collection of 127 cultivars (WHEALBI_CULT) was inoculated with the same two Bgh isolates. Both populations consisted of single seed-derived lines, and an average of 5 parallel plants per line was used in each inoculation assay. For passport data of all lines see Additional file 2: Table S1. Seven days after inoculation, disease was scored by estimating the percentage of leaf area covered by fungal mycelium. Because disease scores were 
variable between different inoculation experiments, they were normalized to internal standards cv. Roland or Morex, as indicated. Phenotypic data of all isolate-genotype combinations are based on two independent inoculation series. SNP calls were derived from exome capture resequencing, and haplotypes were calculated based on the combination of SNP calls per gene. SNP-trait and haplotype-trait associations were calculated in TASSEL v4.1 using a mixed linear model with kinship as random effect. Marker data for kinship calculations were derived from 4032 polymorphic genotyping by sequencing (GBS) markers. Marker-trait associations were assumed significant if the Holm's-corrected $p$ value was $<0.05$ (number or SNP or haplotypes/gene $=$ number of tests).

\section{TIGS and transient over-expression}

TIGS constructs were generated and transferred by particle bombardment into leaf epidermal cells of 7-day-old barley seedlings as described [93]. Leaf segments were inoculated 3 days after the bombardment with Bgh at a density of 140-180 conidia $\mathrm{mm}^{-2}$. Transformed GUS-stained epidermal cells as well as haustoria-containing transformed (susceptible) cells were counted $48 \mathrm{~h}$ after inoculation, and TIGS effects on the susceptibility index (SI) were statistically analyzed [91].

For verification of transgene effects, HVARM1 was excised from a subclone of the bacterial artificial chromosome (BAC) HVVMRXALLhA0581d24 (Acc. Nr. KM979563) as a StuI/SphI fragment and inserted into SmaI/SphI sites of pIPKTA09 [94]. For transient OEX of candidate genes, full-coding sequences were polymerase chain reaction (PCR)

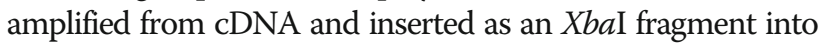
the multiple cloning site of pIPKTA09. Mutations (HvARM1 $^{-\mathrm{L} 286 \mathrm{H}}$ and HvARM1-L308K $)$ were introduced by SDM using the QuikChange Kit (Stratagene, San Diego, CA, USA). The resulting sequence-verified constructs were bombarded into barley as described for BAC clones. For PCR primers used in this study see Additional file 1: Table S9.

For the HvThf1 and HvClpS1 protein degradation assay, $4 \mu \mathrm{g}$ each of plasmid DNA encoding HvPUB15 or HvARM1 plus Thf1:YFP or ClpS1:YFP plus pUbiGUS [93] were co-bombarded into 7-day-old barley cv. Golden Promise. The numbers of YFP-fluorescing cells with plastid-localized signals were counted $24 \mathrm{~h}$ after particle bombardment, followed by GUS-staining [93]. The numbers of GUS-expressing cells were used for normalization of the YFP signal.

\section{Inoculation and evaluation of transgenic plants}

Phenotypic evaluation of Bgh and Bgt interactions was done microscopically on second, detached leaves of 12 14 day-old plants placed on phytoagar plates $(23,2 \mathrm{~cm} \times$ $23,2 \mathrm{~cm}$ ) inoculated at a spore density of 30-40 conidia $\mathrm{mm}^{-2}$. Inoculated leaf segments were incubated for $48 \mathrm{~h}$
(Bgh) or $72 \mathrm{~h}(B g t)$ followed by staining with Coomassie brilliant blue R 250 [95]. The number of growing colonies/leaf area was counted under a standard bright field microscope at $100 \times$ magnification.

\section{Yeast two-hybrid experiments}

Yeast two-hybrid screening was performed according to the Yeast Handbook and manual of Matchmaker ${ }^{\mathrm{mi}}$ Library Construction and Screening Kits (Takara/Clontech Laboratories, Saint-Germain-en-Laye, France). The full-length coding sequence of HvARM1 (1-442 AA) was used to screen a library of $7 \times 10^{6}$ mating events according to [96]. For targeted $\mathrm{Y} 2 \mathrm{H}$ assays, the coding region (1-831 AA) of HvPUB15 was used to test positive prey clones of the HvARM1 screening.

\section{Bimolecular fluorescence complementation and co-immunoprecipitation}

For bimolecular fluorescence complementation $(\mathrm{BiFC})$ of HvARM1 and HvPUB15 proteins with potential plastid interactors, Nicotiana benthamiana plants were grown and agro-infiltrated as described in detail in Additional file 3: Methods S1. For BiFC with HvThf1 and HvClpS1, the wild-type full-length sequences of HvPUB15 or HvARM1, U-box mutants of HvPUB15, the ARM domain (351 to 831 AA) only of HvPUB15, or HvThf1 without N-terminal plastid import signal (-SP) were cloned into $35 \mathrm{~S}: \mathrm{GW}^{\mathrm{GWY}} \mathrm{VY}$ NE-pBar and 35S:: ${ }^{G W}$ VYCE-pBar GATEWAY destination vectors containing the $\mathrm{N}$ - and $\mathrm{C}$-terminal split parts of the enhanced YFP protein Venus, respectively [97]. BiFC constructs were transiently co-expressed by infiltration of Agrobacterium tumefaciens transformed with the corresponding binary vectors, and examined by confocal laser scanning microscopy (CLSM) $48 \mathrm{~h}$ after infiltration. For the development of U-box mutants, a DNA fragment between 709 and 739 bp (from ATG) on the U-box domain of HvPUB15 was excised using BsaXI and replaced by ligating synthetic oligos carrying the respective U-box mutation.

For co-immunoprecipitation (Co-IP), YFP-tagged HvARM1 and HvPUB15 ${ }^{\text {ARM }}$ under the control of the $35 \mathrm{~S}$ promoter were generated by cloning the full-coding sequence of HvARM1 (1-442 AA) or the ARM-repeat region of HvPUB15 (351-831 AA) into pEARLEYGATE104 (Earley et al., 2006). cMyc-Tagged HvThf1 (1-294 AA) and HvClpS1 (1-161 AA) under the control of the CaMV $35 \mathrm{~S}$ promoter were generated by cloning into pGWB418 [98]. Mesophyll-protoplast transformation and co-immunoprecipitation was done as described [99].

\section{Subcellular localization of fluorescent proteins}

For subcellular localization, full-length sequences of HvPUB15, HvARM1, HvThf1, and HvClpS1 were N- and 
C-terminally fused in-frame to YFP in pIPKTA48 and pIPKTA49 vectors (Additional file 1: Figures S11 and S12). Resulting YFP-fusion constructs were transiently expressed in 7-day-old barley leaf segments by particle bombardment and examined after 12-24 h of incubation with or without B. graminis inoculation using CLSM.

\section{Genome-wide search for expressed partial gene duplicates}

To identify expressed partial gene duplicates, a local database was generated using 23,614 full-length cDNA sequences of barley [100], and a Blast search was carried out against itself using the megablast tool in the Galaxy platform [101] with the recommended settings, except the percent identity cutoff was set to $80-99 \%$. To exclude pairs of genes sharing only functional domains, an alignment-to-shorter-gene length ratio of at least 0.8 was set. To identify the open reading frames, a tBlastx analysis of the pairs was carried out using the Galaxy platform. Manual curation was done to exclude non-spliced transcripts and chimeric as well as partial clones. Identified full-length and partial genes were aligned using MAUVE and the MUSCLE algorithm (MegAlign Pro, Version 15.1.0 (155) DNASTAR).

\section{Additional files}

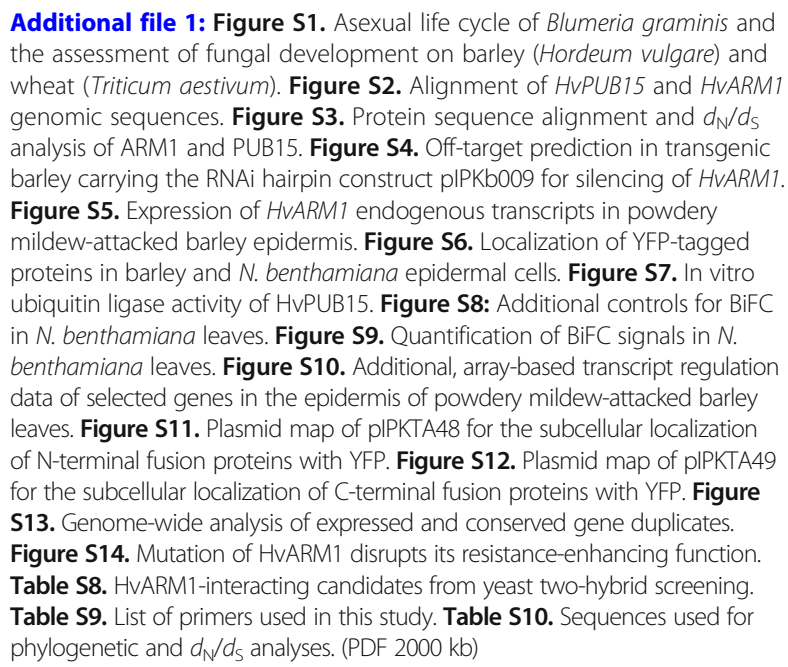
the assessment of fungal development on barley (Hordeum vulgare) and wheat (Triticum aestivum). Figure S2. Alignment of HVPUB15 and HVARM1 genomic sequences. Figure S3. Protein sequence alignment and $d_{N} / d_{S}$ analysis of ARM1 and PUB15. Figure S4. Off-target prediction in transgenic barley carrying the RNAi hairpin construct plPKb009 for silencing of HVARM1. Figure S5. Expression of HVARM1 endogenous transcripts in powdery mildew-attacked barley epidermis. Figure S6. Localization of YFP-tagged proteins in barley and $N$. benthamiana epidermal cells. Figure S7. In vitro ubiquitin ligase activity of HvPUB15. Figure S8: Additional controls for BiFC in N. benthamiana leaves. Figure S9. Quantification of BiFC signals in N. benthamiana leaves. Figure $\mathbf{S 1 0}$. Additional, array-based transcript regulation data of selected genes in the epidermis of powdery mildew-attacked barley leaves. Figure S11. Plasmid map of pIPKTA48 for the subcellular localization of N-terminal fusion proteins with YFP. Figure S12. Plasmid map of pIPKTA49 for the subcellular localization of C-terminal fusion proteins with YFP. Figure S13. Genome-wide analysis of expressed and conserved gene duplicates. Figure S14. Mutation of HvARM1 disrupts its resistance-enhancing function. Table S8. HvARM1-interacting candidates from yeast two-hybrid screening. Table S9. List of primers used in this study. Table S10. Sequences used for phylogenetic and $d_{N} / d_{S}$ analyses. (PDF $2000 \mathrm{~kb}$ )

Additional file 2: Table S1. Passport, phenotypic and gene haplotype data of barley accessions in the WHEALBI populations used for association mapping. Table S2. SNP calls and derived gene haplotypes for HVARM1. Table S3. SNP calls and derived gene haplotypes for HVPUB15. Table S4. Details of partial gene duplicate pairs in the barley genome. Table S5. Evolutionary conservation of partial gene duplicates in Triticeae tribe. Table S6. Transcript regulation of partial duplicates in host (Bgh) and non-host (Bgt) powdery mildew interaction in barley. Table S7. Primary microarray signal intensity data of HVThf1 and HVClpS1. (XLSX $90 \mathrm{~kb}$ )

Additional file 3: Methods S1. Detailed description of materials and methods used in this study. (PDF $183 \mathrm{~kb}$ )

\section{Acknowledgements}

We would like to thank Gabi Brantin, Manuela Knauft, Sonja Gentz, and Cornelia Marthe for their excellent technical assistance.

\section{Funding}

This work was supported by the German Ministry for Education and Research, grant acronyms GABI-nonhost (to P.S.) and GABI-phenome (to P.S., J.KU. and R.H.), by German DFG (ERA-PG project TritNONHOST grant number DFG Schw 848/2-1 to P.S.), by EU FP6 project BIOEXPLOIT (to P.S.), and by EU FP7 project WHEALBI (to P.S. and N.S).

\section{Availability of data and materials}

All data generated or analyzed during this study are included in this published article and its additional files. Sequence information for cDNA clones HO23D08 and $\mathrm{HO} 14 \mathrm{H} 18$ described in Table 1 is provided at https:// www.ncbi.nlm.nih.gov/nuccore under accession numbers DN188354.1 and CK569805.1, respectively [102]. Microarray data are available at ArrayExpress, https://www.ebi.ac.uk/arrayexpress under accession number E-MTAB-2916 [103]. All sequences used for phylogenetic analysis are available at https:// doi.org/10.6084/m9.figshare.c.4092686.v1 [104]. Off-target prediction software si-Fi21 described in Additional file 1: Figure S4b and Additional file 3: Methods S1 is available at https://doi.org/10.5447/ipk/2017/9 [105]. Nucleotide sequences with accession number AK361754 and AK371875 described in Table 1 are publicly available at https://www.ncbi.nlm.nih.gov/nuccore. Whole genome shotgun (WGS) sequence contigs with accession number CAJW010005672, CAJX010121345, CAJV010187631, CAJV010187631,

CAJV010187631 and CAJX010121345 described in Table 1 are publicly available at https://www.ebi.ac.uk/. High-confidence barley genes HORVU3Hr1G113910, HORVU3Hr1G081380, HORVU3Hr1G117760, HORVU2Hr1G041260, HORVU7Hr1G020580, HORVU2Hr1G080670, HORVU3Hr1G059130, HOR-

VU2Hr1G003460 described in Table 1 and Additional file 1: Table S8 are publicly available at http://barlex.barleysequence.org.

\section{Authors' contributions}

PS designed the research, analyzed data, and wrote the article. JKU, RH, MM, MT, and NS designed the research. JR analyzed data and wrote the article. $\mathrm{RH}, \mathrm{DD}, \mathrm{JB}, \mathrm{JKU}$, and $\mathrm{GH}$ discussed results and edited the manuscript. JR, DD, SL, and GH performed research (TIGS and transgenic plants). DD and EB performed research (BAC clone sequencing and rye whole genome sequencing). JR and $\mathrm{CH}$ performed research (yeast two-hybrid screen). JR, $J K L$, and TM performed research (in vivo protein interactions). JR and TR performed research (protein localization). $\mathrm{BL}, \mathrm{AH}, \mathrm{TS}$, and MM performed research (exome capture sequencing, and genotyping by sequencing). DN and MP performed research (association mapping). PS and JB performed the phylogenetic analysis. All authors read and approved the final manuscript.

Ethics approval and consent to participate

Not applicable.

Consent for publication

Not applicable.

Competing interests

The authors declare that they have no competing interests.

\section{Publisher's Note}

Springer Nature remains neutral with regard to jurisdictional claims in published maps and institutional affiliations.

\section{Author details}

${ }^{1}$ Leibniz Institut für Pflanzengenetik und Kulturpflanzenforschung (IPK Gatersleben), Corrensstrasse 3, D-06466 Stadt Seeland, Germany. ${ }^{2}$ Technische Universität München, Emil-Ramann-Straße 2, D-85354 Freising, Germany. ${ }^{3}$ Leibniz Institut für Pflanzenbiochemie, Weinberg 3, D-06120 Halle (Saale), Germany. ${ }^{4}$ Technische Universität München, Liesel-Beckmann-Straße 2, D-85354 Freising, Germany. ${ }^{5}$ Parco Technologico Padano, Via Einstein, Loc. Cascina Codazza, 26900 Lodi, Italy. ${ }^{6}$ Albert-Ludwigs-Universität Freiburg, Institut für Biologie II, Zellbiologie, D-79104 Freiburg, Germany. 
Received: 11 December 2017 Accepted: 4 July 2018 Published online: 15 August 2018

\section{References}

1. Macho AP, Zipfel C. Plant PRRs and the activation of innate immune signaling. Mol Cell. 2014;54:263-72.

2. Toruno TY, Stergiopoulos I, Coaker G. Plant-pathogen effectors: cellular probes interfering with plant defenses in spatial and temporal manners. Annu Rev Phytopathol. 2016;54:419-41.

3. Schulze-Lefert P, Panstruga R. A molecular evolutionary concept connecting nonhost resistance, pathogen host range, and pathogen speciation. Trends Plant Sci. 2011;16:117-25.

4. St Clair DA. Quantitative disease resistance and quantitative resistance loci in breeding. Annu Rev Phytopathol. 2010;48:247-68.

5. Kou YJ, Wang SP. Broad-spectrum and durability: understanding of quantitative disease resistance. Curr Opin Plant Biol. 2010;13:181-5.

6. Niks RE, Qi XQ, Marcel TC. Quantitative resistance to biotrophic filamentous plant pathogens: concepts, misconceptions, and mechanisms. Annu Rev Phytopathol. 2015:53:445-70.

7. Yahiaoui N, Brunner S, Keller B. Rapid generation of new powdery mildew resistance genes after wheat domestication. Plant J. 2006;47:85-98.

8. Sperschneider J, Ying H, Dodds PN, Gardiner DM, Upadhyaya NM, Singh KB, Manners JM, Taylor JM. Diversifying selection in the wheat stem rust fungus acts predominantly on pathogen-associated gene families and reveals candidate effectors. Front Plant Sci. 2014;5:372.

9. Badouin H, Gladieux P, Gouzy J, Siguenza S, Aguileta G, Snirc A, Le Prieur S, Jeziorski C, Branca A, Giraud T. Widespread selective sweeps throughout the genome of model plant pathogenic fungi and identification of effector candidates. Mol Ecol. 2017;26:2041-62.

10. Plissonneau C, Benevenuto J, Mohd-Assaad N, Fouché S, Hartmann FE, Croll D. Using population and comparative genomics to understand the genetic basis of effector-driven fungal pathogen evolution. Front Plant Sci. 2017:8: 119. https://doi.org/10.3389/fpls.2017.00119.

11. Wei FS, Wong RA, Wise RP. Genome dynamics and evolution of the Mla (powdery mildew) resistance locus in barley. Plant Cell. 2002;14:1903-17.

12. Hu PS, Wise RP. Diversification of Lrk/Tak kinase gene clusters is associated with subfunctionalization and cultivar-specific transcript accumulation in barley. Funct Integr Genomics. 2008;8:199-209.

13. Hu XY, Burghes AH, Ray PN, Thompson MW, Murphy EG, Worton RG. Partial gene duplication in Duchenne and Becker muscular dystrophies. J Med Genet. 1988:25:369-76.

14. Strout MP, Marcucci G, Bloomfield CD, Caligiuri MA. The partial tandem duplication of ALL1 (MLL) is consistently generated by Alu-mediated homologous recombination in acute myeloid leukemia. Proc Natl Acad Sci U S A. 1998;95:2390-5.

15. Devlin RH, Deeb S, Brunzell J, Hayden MR. Partial gene duplication involving exon-alu interchange results in lipoprotein-lipase deficiency. Am J Hum Genet. 1990;46:112-9.

16. Kitano T, Tian W, Umetsu K, Yuasa I, Yamazaki K, Saitou N, Osawa M. Origin and evolution of gene for prolactin-induced protein. Gene. 2006:383:64-70.

17. Grishkevich V, Yanai I. Gene length and expression level shape genomic novelties. Genome Res. 2014;24:1497-503.

18. Korithoski B, Kolaczkowski O, Mukherjee K, Kola R, Earl C, Kolaczkowski B. Evolution of a novel antiviral immune-signaling interaction by partial-gene duplication. PLoS One. 2015;10:e0137276.

19. Wicker T, Mayer KFX, Gundlach H, Martis M, Steuernagel B, Scholz U, Simkova H, Kubalakova M, Choulet F, Taudien S, et al. Frequent gene movement and pseudogene evolution is common to the large and complex genomes of wheat, barley, and their relatives. Plant Cell. 2011:23:1706-18

20. Akhunov ED, Sehgal S, Liang HQ, Wang SC, Akhunova AR, Kaur G, Li WL, Forrest $\mathrm{KL}$, See $\mathrm{D}$, Simkova $\mathrm{H}$, et al. Comparative analysis of syntenic genes in grass genomes reveals accelerated rates of gene structure and coding sequence evolution in polyploid wheat. Plant Physiol. 2013;161:252-65.

21. Bauer E, Schmutzer T, Barilar I, Mascher M, Gundlach H, Martis MM, Twardziok SO, Hackauf B, Gordillo A, Wilde P, et al. Towards a wholegenome sequence for rye (Secale cereale L.). Plant J. 2017;89:853-69.

22. Panstruga $R$, Schulze-Lefert $P$. Live and let live: insights into powdery mildew disease and resistance. Mol Plant Pathol. 2002:3:495-502.

23. Oerke EC. Crop losses to pests. J Agric Sci. 2006;144:31-43.
24. Huckelhoven R. Cell wall-associated mechanisms of disease resistance and susceptibility. Annu Rev Phytopathol. 2007:45:101-27.

25. Collinge DB. Cell wall appositions: the first line of defence. J Exp Bot. 2009;60:351-2.

26. Huckelhoven R, Panstruga R. Cell biology of the plant-powdery mildew interaction. Curr Opin Plant Biol. 2011;14:738-46.

27. Pedersen C, van Themaat EVL, McGuffin LJ, Abbott JC, Burgis TA, Barton G, Bindschedler LV, Lu XL, Maekawa T, Wessling R, et al. Structure and evolution of barley powdery mildew effector candidates. BMC Genomics. 2012;13:694.

28. Abramovitch RB, Janjusevic R, Stebbins CE, Martin GB. Type III effector AvrPtoB requires intrinsic E3 ubiquitin ligase activity to suppress plant cell death and immunity. Proc Natl Acad Sci U S A. 2006:103:2851-6.

29. Angot A, Peeters N, Lechner E, Vailleau F, Baud C, Gentzbittel L, Sartorel E, Genschik P, Boucher C, Genin SP. Ralstonia solanacearum requires F-box-like domain-containing type III effectors to promote disease on several host plants. Proc Natl Acad Sci U S A. 2006:103:14620-5.

30. Rosebrock TR, Zeng LR, Brady JJ, Abramovitch RB, Xiao FM, Martin GB. A bacterial E3 ubiquitin ligase targets a host protein kinase to disrupt plant immunity. Nature. 2007:448:370-U313.

31. Groll M, Schellenberg B, Bachmann AS, Archer CR, Huber R, Powell TK, Lindow S, Kaiser M, Dudler R. A plant pathogen virulence factor inhibits the eukaryotic proteasome by a novel mechanism. Nature. 2008;452:755-8.

32. Spallek T, Robatzek S, Gohre V. How microbes utilize host ubiquitination. Cell Microbiol. 2009;11:1425-34.

33. Bos JIB, Armstrong MR, Gilroy EM, Boevink PC, Hein I, Taylor RM, Tian ZD, Engelhardt S, Vetukuri RR, Harrower B, et al. Phytophthora infestans effector AVR3a is essential for virulence and manipulates plant immunity by stabilizing host E3 ligase CMPG1. Proc Natl Acad Sci U S A. 2010;107:9909-14.

34. Nomura K, Mecey C, Lee YN, Imboden LA, Chang JH, He SY. Effector-triggered immunity blocks pathogen degradation of an immunity-associated vesicle traffic regulator in Arabidopsis. Proc Natl Acad Sci U S A. 2011;108:10774-9.

35. Vierstra RD. The ubiquitin-26S proteasome system at the nexus of plant biology. Nat Rev Mol Cell Biol. 2009;10:385-97.

36. Trujillo M, Shirasu K. Ubiquitination in plant immunity. Curr Opin Plant Biol. 2010:13:402-8.

37. Schweizer P. Nonhost resistance of plants to powdery mildew - new opportunities to unravel the mystery. Physiol Mol Plant Pathol. 2007;70:3-7.

38. Sadanandom A, Bailey M, Ewan R, Lee J, Nelis S. The ubiquitin-proteasome system: central modifier of plant signalling. New Phytol. 2012;196:13-28.

39. Douchkov D, Lück S, Johrde A, Nowara D, Himmelbach A, Rajaraman J, Stein N, Sharma R, Kilian B, Schweizer P. Discovery of genes affecting resistance of barley to adapted and non-adapted powdery mildew fungi. Genome Biol. 2014;15:518.

40. Azevedo C, Santos-Rosa MJ, Shirasu K. The U-box protein family in plants. Trends Plant Sci. 2001;6:354-8.

41. Mudgil Y, Shiu SH, Stone SL, Salt JN, Goring DR. A large complement of the predicted Arabidopsis ARM repeat proteins are members of the U-box E3 ubiquitin ligase family. Plant Physiol. 2004;134:59-66.

42. Zeng LR, Park CH, Venu RC, Gough J, Wang GL. Classification, expression pattern, and E3 ligase activity assay of rice U-box-containing proteins. Mol Plant. 2008;1:800-15.

43. Bernhardt N, Brassac J, Kilian B, Blattner FR. Dated tribe-wide whole chloroplast genome phylogeny indicates recurrent hybridizations within Triticeae. BMC Evol Biol. 2017:17:141.

44. Park JJ, Yi J, Yoon J, Cho LH, Ping J, Jeong HJ, Cho SK, Kim WT, An G. OsPUB15, an E3 ubiquitin ligase, functions to reduce cellular oxidative stress during seedling establishment. Plant J. 2011;65:194-205.

45. Close TJ, Bhat PR, Lonardi S, Wu Y, Rostoks N, Ramsay L, Druka A, Stein N, Svensson JT, Wanamaker $\mathrm{S}$, et al. Development and implementation of high-throughput SNP genotyping in barley. BMC Genomics. 2009:10:582.

46. Huang J, Taylor JP, Chen JG, Uhrig JF, Schnell DJ, Nakagawa T, Korth KL, Jones AM. The plastid protein THYLAKOID FORMATION1 and the plasma membrane G-protein GPA1 interact in a novel sugar-signaling mechanism in Arabidopsis. Plant Cell. 2006;18:1226-38.

47. Nishimura K, Asakura Y, Friso G, Kim J, Oh SH, Rutschow H, Ponnala L, van Wijk KJ. ClpS1 Is a conserved substrate selector for the chloroplast Clp protease system in Arabidopsis. Plant Cell. 2013;25:2276-301.

48. Koegl M, Hoppe T, Schlenker S, Ulrich HD, Mayer TU, Jentsch S. A nove ubiquitination factor, E4, is involved in multiubiquitin chain assembly. Cell. 1999;96:635-44. 
49. Nelson BK, Cai X, Nebenfuhr A. A multicolored set of in vivo organelle markers for co-localization studies in Arabidopsis and other plants. Plant J. 2007;51:1126-36.

50. Katju V, Lynch $M$. The structure and early evolution of recently arisen gene duplicates in the Caenorhabditis elegans genome. Genetics. 2003;165:1793-803.

51. Leister D. Tandem and segmental gene duplication and recombination in the evolution of plant disease resistance genes. Trends Genet. 2004;20:116-22.

52. Himmelbach A, Liu L, Zierold U, Altschmied L, Maucher H, Beier F, Muller D, Hensel G, Heise A, Schutzendubel A, et al. Promoters of the barley germinlike GER4 gene cluster enable strong transgene expression in response to pathogen attack. Plant Cell. 2010;22:937-52.

53. Luo MC, Gu YQ, You FM, Deal KR, Ma YQ, Hu YQ, Huo NX, Wang Y, Wang $J R$, Chen SY, et al. A 4-gigabase physical map unlocks the structure and evolution of the complex genome of Aegilops tauschii, the wheat Dgenome progenitor. Proc Natl Acad Sci U S A. 2013;110:7940-5.

54. Mascher M, Richmond TA, Gerhardt DJ, Himmelbach A, Clissold L, Sampath D, Ayling S, Steuernagel B, Pfeifer M, D'Ascenzo M, et al. Barley whole exome capture: a tool for genomic research in the genus Hordeum and beyond. Plant J. 2013;76:494-505.

55. Blanc $\mathrm{G}$, Wolfe $\mathrm{KH}$. Functional divergence of duplicated genes formed by polyploidy during Arabidopsis evolution. Plant Cell. 2004;16:1679-91.

56. Roulin A, Auer PL, Libault M, Schlueter J, Farmer A, May G, Stacey G, Doerge RW, Jackson SA. The fate of duplicated genes in a polyploid plant genome. Plant J. 2013;73:143-53.

57. Hughes TE, Langdale JA, Kelly S. The impact of widespread regulatory neofunctionalization on homeolog gene evolution following wholegenome duplication in maize. Genome Res. 2014;24:1348-55.

58. Panchy N, Lehti-Shiu M, Shiu SH. Evolution of gene duplication in plants. Plant Physiol. 2016;171:2294-316.

59. Woodson JD, Joens MS, Sinson AB, Gilkerson J, Salome PA, Weigel D, Fitzpatrick JA, Chory J. Ubiquitin facilitates a quality-control pathway that removes damaged chloroplasts. Science. 2015;350:450-4.

60. Zhou J, Lu D, Xu G, Finlayson SA, He P, Shan L. The dominant negative ARM domain uncovers multiple functions of PUB13 in Arabidopsis immunity, flowering, and senescence. J Exp Bot. 2015;66:3353-66.

61. van der Hoorn RAL, Kamoun S. From Guard to Decoy: A new model for perception of plant pathogen effectors. Plant Cell. 2008;20:2009-17.

62. Kim SH, Qi D, Ashfield T, Helm M, Innes RW. Using decoys to expand the recognition specificity of a plant disease resistance protein. Science. 2016;351:684-7.

63. Wang J, Qu B, Dou S, Li L, Yin DD, Pang ZQ, Zhou ZZ, Tian MM, Liu GZ, Xie Q, et al. The E3 ligase OsPUB15 interacts with the receptor-like kinase PID2 and regulates plant cell death and innate immunity. BMC Plant Biol. 2015;15:49.

64. Scholes JD, Lee PJ, Horton P, Lewis DH. Invertase: understanding changes in the photosynthetic and carbohydrate metabolism of barley leaves infected with powdery mildew. New Phytol. 1994;126:213-22.

65. Chen LQ, Hou BH, Lalonde S, Takanaga H, Hartung ML, Qu XQ, Guo WJ, Kim JG, Underwood W, Chaudhuri B, et al. Sugar transporters for intercellular exchange and nutrition of pathogens. Nature. 2010;468:527-32.

66. Chen LQ, Qu XQ, Hou BH, Sosso D, Osorio S, Fernie AR, Frommer WB. Sucrose efflux mediated by SWEET proteins as a key step for phloem transport. Science. 2012;335:207-11.

67. Manning VA, Hardison LK, Ciuffetti LM. Ptr ToxA interacts with a chloroplastlocalized protein. Mol Plant-Microbe Interact. 2007;20:168-77.

68. Manning VA, Chu AL, Scofield SR, Ciuffetti LM. Intracellular expression of a host-selective toxin, ToxA, in diverse plants phenocopies silencing of a ToxA-interacting protein, ToxABP1. New Phytol. 2010;187:1034-47.

69. Pandelova I, Figueroa M, Wilhelm $\sqcup$, Manning VA, Mankaney AN, Mockler TC, Ciuffetti LM. Host-selective toxins of Pyrenophora tritici-repentis induce common responses associated with host susceptibility. PLoS One. 2012;7:e40240.

70. Hamel L-P, Sekine K-T, Wallon T, Sugiwaka Y, Kobayashi K, Moffett P. The chloroplastic protein THF1 interacts with the coiled-coil domain of the disease resistance protein $\mathrm{N}$ ' and regulates light-dependent cell death. Plant Physiol. 2016;171:658-74.

71. Wei J, Qiu X, Chen L, Hu W, Hu R, Chen J, Sun L, Li L, Zhang H, Lv Z, Shen $\mathrm{G}$. The E3 ligase AtCHIP positively regulates Clp proteolytic subunit homeostasis. J Exp Bot. 2015;66:5809-20.

72. Mascher M, Gundlach H, Himmelbach A, Beier S, Twardziok SO, Wicker T, Radchuk V, Dockter C, Hedley PE, Russell J, et al. A chromosome conformation capture ordered sequence of the barley genome. Nature. 2017;544:427-33.
73. Hensel G, Valkov V, Middlefell-Williams J, Kumlehn J. Efficient generation of transgenic barley: the way forward to modulate plant-microbe interactions. J Plant Physiol. 2008;165:71-82.

74. Schmutzer T. Scaffolds of rye (Secale cereale L.) inbred line Lo7- version 2. In: Leibniz Institute of Plant Genetics and Crop Plant Research (IPK), Seeland OT Gatersleben, Corrensstraße 3, 06466, Germany; 2016. https://doi.org/10. 5447/ipk/2016/56.

75. International Wheat Genome Sequencing Consortium. A chromosomebased draft sequence of the hexaploid bread wheat (Triticum aestivum) genome. Science. 2014;345:1251788.

76. Katoh K, Standley DM. MAFFT multiple sequence alignment software version 7: improvements in performance and usability. Mol Biol Evol. 2013;30:772-80

77. Kearse M, Moir R, Wilson A, Stones-Havas S, Cheung M, Sturrock S, Buxton S, Cooper A, Markowitz S, Duran C, et al. Geneious Basic: an integrated and extendable desktop software platform for the organization and analysis of sequence data. Bioinformatics. 2012;28:1647-9.

78. Darriba D, Taboada GL, Doallo R, Posada D. jModelTest 2: more models, new heuristics and parallel computing. Nat Methods. 2012;9:772.

79. Akaike $\mathrm{H}$. Information theory and an extension of the maximum likelihood principle. In: Parzen E, Tanabe K, Kitagawa G, editors. Selected papers of Hirotugu Akaike. New York: Springer; 1998. p. 199-213.

80. Akaike $\mathrm{H}$. A new look at the statistical model identification. In: Parzen $\mathrm{E}$, Tanabe K, Kitagawa G, editors. Selected papers of Hirotugu Akaike. New York: Springer; 1998. p. 215-22.

81. Lanave C, Preparata G, Saccone C, Serio G. A new method for calculating evolutionary substitution rates. J Mol Evol. 1984;20:86-93.

82. Yang ZH. Maximum likelihood phylogenetic estimation from DNA sequences with variable rates over sites: approximate methods. J Mol Evol. 1994;39:306-14.

83. Stamatakis A. RAxML version 8: a tool for phylogenetic analysis and postanalysis of large phylogenies. Bioinformatics. 2014;30:1312-3.

84. Yang Z. PAML: a program package for phylogenetic analysis by maximum likelihood. Comput Appl Biosci. 1997;13:555-6.

85. Jeffares DC, Tomiczek B, Sojo V, dos Reis M. A beginners guide to estimating the non-synonymous to synonymous rate ratio of all proteincoding genes in a genome. Methods Mol Biol. 2015;1201:65-90.

86. Goldman N, Yang Z. A codon-based model of nucleotide substitution for protein-coding DNA sequences. Mol Biol Evol. 1994;11:725-36.

87. Yang Z, Nielsen R. Synonymous and nonsynonymous rate variation in nuclear genes of mammals. J Mol Evol. 1998;46:409-18.

88. Nielsen R, Yang Z. Likelihood models for detecting positively selected amino acid sites and applications to the HIV-1 envelope gene. Genetics. 1998;148:929-36.

89. Yang Z, Wong WS, Nielsen R. Bayes empirical bayes inference of amino acid sites under positive selection. Mol Biol Evol. 2005;22:1107-18.

90. Li H, Durbin R. Fast and accurate short read alignment with BurrowsWheeler transform. Bioinformatics. 2009;25:1754-60.

91. Spies A, Korzun V, Bayles R, Rajaraman J, Himmelbach A, Hedley PE, Schweizer $P$. Allele mining in barley genetic resources reveals genes of race-non-specific powdery mildew resistance. Front Plant Sci. 2011;2:113.

92. Šurlan-Momirović G, Flath K, Silvar C, Branković G, Kopahnke D, Knežević D, Schliephake E, Ordon F, Perović D. Exploring the Serbian GenBank barley (Hordeum vulgare L. subsp. vulgare) collection for powdery mildew resistance. Genet Resour Crop Evol. 2016;63:275-87.

93. Douchkov D, Nowara D, Zierold U, Schweizer P. A high-throughput genesilencing system for the functional assessment of defense-related genes in barley epidermal cells. Mol Plant-Microbe Interact. 2005;18:755-61.

94. Zimmermann G, Baumlein H, Mock HP, Himmelbach A, Schweizer P. The multigene family encoding germin-like proteins of barley. Regulation and function in basal host resistance. Plant Physiol. 2006;142:181-92.

95. Schweizer $P$, Gees R, Mosinger E. Effect of jasmonic acid on the interaction of barley (Hordeum vulgare L.) with the powdery mildew Erysiphe graminis f.sp. hordei. Plant Physiol. 1993;102:503-11.

96. Hoefle C, Huesmann C, Schultheiss H, Bornke F, Hensel G, Kumlehn J, Hückelhoven R. A barley ROP GTPase ACTIVATING PROTEIN associates with microtubules and regulates entry of the barley powdery mildew fungus into leaf epidermal cells. Plant Cell. 2011;23:2422-39.

97. Thormahlen I, Meitzel T, Groysman J, Ochsner AB, von Roepenack-Lahaye E, Naranjo B, Cejudo FJ, Geigenberger P. Thioredoxin f1 and NADPHdependent thioredoxin reductase $C$ have overlapping functions in regulating photosynthetic metabolism and plant growth in response to varying light conditions. Plant Physiol. 2015;169:1766-86. 
98. Nakagawa T, Kurose T, Hino T, Tanaka K, Kawamukai M, Niwa Y, Toyooka K, Matsuoka K, Jinbo T, Kimura T. Development of series of gateway binary vectors, pGWBs, for realizing efficient construction of fusion genes for plant transformation. J Biosci Bioeng 2007:104:34-41.

99. Stegmann M, Anderson RG, Ichimura K, Pecenkova T, Reuter P, Zarsky V, McDowell JM, Shirasu K, Trujillo M. The ubiquitin ligase PUB22 targets a subunit of the exocyst complex required for PAMP-triggered responses in Arabidopsis. Plant Cell. 2012;24:4703-16.

100. Matsumoto T, Tanaka T, Sakai H, Amano N, Kanamori H, Kurita K, Kikuta A, Kamiya $\mathrm{K}$, Yamamoto M, Ikawa $\mathrm{H}$, et al. Comprehensive sequence analysis of 24,783 barley full-length cDNAs derived from 12 clone libraries. Plant Physiol. 2011;156:20-8.

101. Afgan $E$, Baker D, van den Beek M, Blankenberg D, Bouvier D, Cech M Chilton J, Clements D, Coraor N, Eberhard C, et al. The Galaxy platform for accessible, reproducible and collaborative biomedical analyses: 2016 update. Nucleic Acids Res. 2016;44:W3-W10.

102. Zierold U, Scholz U, Schweizer P. Transcriptome analysis of mlo-mediated resistance in the epidermis of barley. Mol Plant Pathol. 2005;6:139-51.

103. Delventhal R, Rajaraman J, Stefanato FL, Rehman S, Aghnoum R, McGrann GRD, Bolger M, Usadel B, Hedley PE, Boyd L, et al. A comparative analysis of nonhost resistance across the two Triticeae crop species wheat and barley. BMC Plant Biol. 2017:17:232.

104. Brassac J: ARM1 and PUB15 coding sequences for phylogenetic tree. In Data Sets figshare; 2018. https://doi.org/10.6084/m9.figshare.c.4092686.v1

105. Lueck S: siFi_ Software for long double-stranded RNAi-target design and off-target prediction. Leibniz Institute of Plant Genetics and Crop Plant Research (IPK), Seeland OT Gatersleben, Corrensstraße 3, 06466, Germany; 2017. https://doi.org/10.5447/ipk/2017/9.

106. Schweizer P, Pokorny J, Abderhalden O, Dudler R. A transient assay system for the functional assessment of defense-related genes in wheat. Mol PlantMicrobe Interact. 1999;12:647-54.

Ready to submit your research? Choose BMC and benefit from:

- fast, convenient online submission

- thorough peer review by experienced researchers in your field

- rapid publication on acceptance

- support for research data, including large and complex data types

- gold Open Access which fosters wider collaboration and increased citations

- maximum visibility for your research: over $100 \mathrm{M}$ website views per year

At $\mathrm{BMC}$, research is always in progress.

Learn more biomedcentral.com/submissions 